WAKE FOREST JOURNAL OF BUSINESS

AND INTELLECTUAL PROPERTY LAW

\title{
COPYRIGHT AND CREATIVE ARTIFICIAL INTELLIGENCE (AI) SYSTEMS: A TWENTY-FIRST CENTURY APPROACH TO AUTHORSHIP OF AI-GENERATED WORKS IN THE UNITED STATES
}

\author{
Atilla Kasap ${ }^{\dagger}$
}

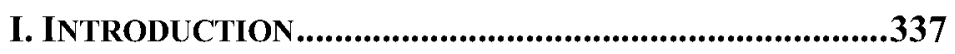

II. WHAT IS ARTIFICIAL INTELLIGENCE? .....................338

III. ARE AI-GENERATED WORKS ELIGIBLE FOR COPYRIGHT PROTECTION? ......................................343

A. A FIXED INTANGIBLE MEDIUM OF EXPRESSION.........343

B. CREATIVITY ......................................................... 343

1. Creativity Standards: Feist ..................................343

2. Tracing the Locus of Difference Between Human and Computational Creativity ................................. 344

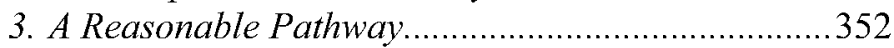

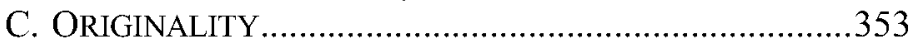

1. The Constitutional and Statutory Grounds ..............353

2. The Development of Case Law............................355

3. The Evaluation of Case Law and Suggestions for the Future................................................................ 358

$\dagger$ (c) 2019 Atilla Kasap graduated from Istanbul University Faculty of Law in 2013. He gained significant experience working in Turkish law firms as a legal intern and attorney. He then pursued an LL.M. degree at Queen Mary University of London, graduating with honors. He is currently an SJD Candidate at Wake Forest University School of Law. The author acknowledges the funding received towards his graduate study from the Ministry of National Education of Turkish Republic. The author would like to thank Prof. Michael D. Green and Dr. Apostolos Chronopoulos for their invaluable comments. The author would also like to thank the Wake Forest Journal of Business and Intellectual Property Law executive board and staff members for preparing this note for publication. Finally, the author would like to thank his wife, siblings, parents, parents-in-law, and the Kinnisons for their encouragement and moral support throughout his educational pursuits. 
IV. JUSTIFYING AI-GENERATED WORKS: THE

UTILITARIAN APPROACH..............................................361

V. CANDIDATES FOR AUTHORSHIP .................................364

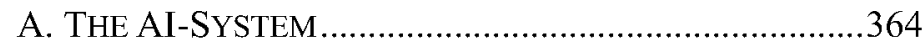

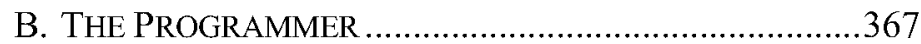

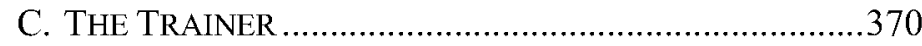

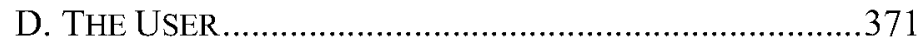

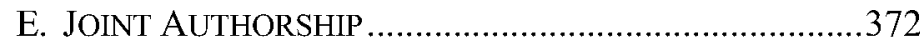

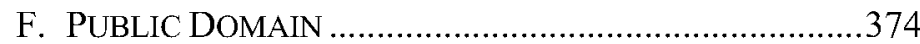

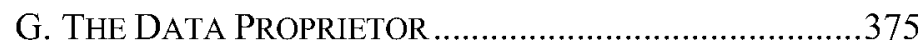

VI. STRIKING A BALANCE ...........................................376

VII. CONCLUSION ..............................................................378 


\section{INTRODUCTION}

Complex Artificial Intelligence ("AI")-systems can generate original works as if they were human, yet with little or no human intervention. Nonetheless, the development of case law concerning copyright has implicitly centered on human creativity and originality, two qualities that a work must embody to be eligible for protection. ${ }^{1}$ Moreover, copyright law has adapted over time, as technological innovations have confronted legislators and courts with new challenges in conception and application. Harmonizing the human role in copyright and technological innovations is therefore of the utmost importance if the United States' constitutional principle of furthering science is to be maintained.

The difference between human creativity and computational creativity is the first and most crucial question that needs to be answered. This is because many AI processes are currently being employed to mimic human capacities. The state of the art in AI should be clarified to demonstrate the role that humans play in creative machines and the creative output of machines. Whether, as a matter of empirical fact, AI-systems are capable of all the creative capacities that humans possess is directly related to the following question: who is the author of AI-generated works? In other words, to whom are economic rights in authorship to be transferred to and who has standing before a court in the case of infringement issues and the like?

It has been argued that since machines need no incentives to create anything, the public should freely benefit from their creations. ${ }^{2}$ Since machine production is less costly than its human counterpart, whether or not a utilitarian approach is applicable to AI-generated works is highly relevant to maintaining productivity. The growth of AI is expected to trigger significant changes not only in the United States' economy ${ }^{3}$ but also in human history. ${ }^{4}$ Moreover, the United States' stance on the principles of authorship concerning AI will likely trigger

\footnotetext{
${ }^{1}$ Feist Publ'ns, Inc. v. Rural Tel. Serv. Co., 499 U.S. 340, 345 (1991).

${ }^{2}$ Robert Yu, The Machine Author: What Level of Copyright Protection is Appropriate for Fully Independent Computer-Generated Works?, 165 U. PA. L. REV. 1245,1270 (2017).

${ }^{3}$ See, e.g., Jason Furman et Al., Artificial Intelligence, Automation, AND THE ECONOMY 1 (2016) (discussing AI's possible future implications for the U.S. economy).

${ }^{4}$ Stephen Hawking et al., Transcending Complacency on Superintelligent Machines, HuffPost (Apr. 19, 2014, 9:14 AM), https://www.huffingtonpost.com/stephen-hawking/artificialintelligenceb5174265.html ("Success in creating AI would be the biggest event in human history.").
} 
a domino effect in other jurisdictions given the United States' pioneering position in technology and law.

Addressing the above-mentioned questions is ultimately an interdisciplinary exercise involving fields such as philosophy, cognitive science, computer science and law. This note does not seek to address whether computers possess the features that humans possess in the creative process, but rather to highlight the role that human agency and passion play in the development of creative AI-systems and legal implications therein, as related to copyright. The role of human agency is likely to be decisive in the allocation of authorship in questions of AI creativity, as legislative and judicial bodies have in the past considered it when confronted with new technological developments or advances. ${ }^{5}$

This note is divided into five sections. The first section provides a brief definition, preliminary history, and summary of the latest developments of AI technology. This is followed by an in-depth investigation into the copyrightability of AI-generated works in the second section. Importantly, the second section will trace the locus of difference between human creativity and computational creativity and propose policy changes in the application of the notion of the originality which serves as a requisite for the allocation of authorship for copyright purposes. The third section will explore reasons to accept AI-generated works as copyrightable based on utilitarian grounds. Having thus established the grounds of copyright protection eligibility for AIgenerated works, the fourth section will determine how authorship of these works is best attributed or recognized through a comprehensive analysis of the merits of seven plausible options: (i) the AI system itself as author; (ii) the programmer as author; (iii) the trainer as author; (iv) the user as author; (v) joint authorship; (vi) public domain or; (vii) the data proprietor. The final section proposes a solution to who should be accepted as the author of AI-generated works that better serves constitutional purposes and balances the many interests that are likely to arise between the various actors who develop creative machines or who lawfully obtain such machines.

\section{WHAT IS ARTIFICIAL INTELLIGENCE?}

The term "artificial intelligence" was first used by John McCarthy in 1956 at a workshop exploring ways in which machines might be

\footnotetext{
${ }^{5}$ Janna Anderson et al., Concerns About Human Agency, Evolution, and Survival, PEW RESEARCH CTR. (Dec. 10, 2018), https://www.pewinternet.org/2018/12/10/concerns-about-human-agency-evolutionand-survival/.
} 
employed to mimic features of human intelligence. ${ }^{6}$ Although sixty years have passed since the term was coined, there is still no universally accepted definition of AI. ${ }^{7}$ Stuart Russell and Peter Norvig, two prominent scholars in the field of AI, attempt to define AI into the following approaches: (i) the Turing Test approach; ${ }^{8}$ (ii) the cognitive modeling approach; ${ }^{9}$ (iii) the laws of thought approach, ${ }^{10}$ and; (iv) the rational agent approach. ${ }^{11}$ Russell and Norvig adopt the last method, which defines AI as an agent that acts in order to achieve an optimal result or, if there is ambiguity, the best predictable result. ${ }^{12}$ In this approach, the capacity of the rational agent to accurately deduce conclusions from stated premises is crucial, since a core dimension of acting rationally is the ability to infer logically which particular action from a set of choices will result in one's objective being attained. ${ }^{13}$ McCarthy, similarly, viewed intelligence as the computational dimension of the ability to accomplish goals in the world, arguing that the concluding theme of $\mathrm{AI}$ is, in this view, intelligent machine and intelligent computer software. ${ }^{14}$

Matthew Scherer, another scholar in the field, rightfully indicates that such a broad definition of intelligence within regulation or legislation poses tremendous challenges. ${ }^{15}$ This is because the notion of "goals" embodied in the rational actor approach necessarily implies

${ }^{6}$ John McCarthy et al., A Proposal for the Dartmouth Summer Research Project on Artificial Intelligence, 27 AI MAG., no. 4, 2006, at 12-13.

${ }^{7}$ John McCarthy, What is Artificial Intelligence?, (Nov. 12, 2007), $\mathrm{http}: / / j m c . s t a n f o r d . e d u / a r t i f i c i a l-i n t e l l i g e n c e / i n d e x . h t m l$ (stating that even researchers in the field have yet to reach a consensus on the definition of $\mathrm{AI}$ ).

${ }^{8}$ StUart Russell \& Peter Norvig, Artificial Intelligence: A MODERN ApproACH 2 (Michael Hirsch et al. eds., 3d ed. 2010) (discussing that the Turing Test approach follows Alan Turing's proposal to assess the computer as having successfully passed the test if the human interrogator cannot determine whether the written responses produced by it derive from a human or a computer. The test does not assess direct physical interaction since this is not a decisive factor for assessing intelligence); see generally A. M. Turing, Computing Machinery and Intelligence, 49 MIND 433 (1950).

${ }^{9}$ Russell \& Norvig, supra note 8 , at 3 (defining AI under this approach by investigating how the human mind works through self-examination, psychological experimentation and neuroimaging).

${ }^{10} I d$. at 4 .

${ }^{11} I d$. at $4-5$.

${ }^{12} \mathrm{Id}$.

${ }^{13} \mathrm{Id}$. (indicating that accurate deduction is not always rational because, under some conditions, there is no demonstrably optimal form of action, despite some action being required.).

${ }^{14}$ McCarthy, supra note 6, at 12.

${ }^{15}$ Matthew U. Scherer, Regulating Artificial Intelligence Systems: Risks, Challenges, Competencies, and Strategies, 29 HARV. J. L. \& TECH. 353, 361 (2016). 
"intention."16 Here, we confront the question of whether or when a machine might be said to have "intent," which requires a metaphysical inquiry rather than a juridical or scientific one. ${ }^{17}$ The difficulty for law lies in defining the notion of "goal" or objective in a way that precludes prerequisites related to intent and self-awareness. Therefore, a pure rational actor approach to defining intelligence is inadequate for judicial purposes. ${ }^{18}$ Scherer thus provides a definition of AI more amenable to legal application; namely, as machines that have the ability to do tasks that, if performed by a human, could be said to require intelligence. ${ }^{19}$ To distinguish between $\mathrm{AI}$ as a notion and $\mathrm{AI}$ as a tangible technology, Scherer prefers the term "AI system" for the latter. AI-systems, in this view, incorporate both hardware and software, including robots, computer programs (employed by either a single machine or a computer network), or any combination of components that deploy AI in general. ${ }^{20}$

Since free will, emotions, and intentions play a significant role in human artistic endeavors, a legal definition of AI should not incorporate such vague requisites, because they are still not computerized efficiently. As has been explained, the scope of this note is limited to the interaction of AI and copyright, leaving scientific discussion to other experts. With this in mind, this note defines AI as sophisticated software, hardware, or algorithmic mechanisms that are capable of generating a copyrightable work by employing cutting-edge methods developed by AI researchers, such as genetic algorithms, artificial neural networks, machine learning, and unsupervised learning. Human intervention in this process is so minimal, if not absent, that allocating authorship for copyright purposes becomes the main issue.

Leaving aside the authorship of AI-generated work for a moment, we turn to a brief introduction of the technology itself. This is important given that the ways in which machine outputs can mimic human intelligence are not always easy to grasp. Scholars have been grappling with this problem since the dawn of the computer age. ${ }^{21}$ In his famous essay on the issue, "Computing Machinery and Intelligence," Alan Turing questioned whether: (i) computers would be created for imitating intelligence; (ii) computer intelligence might be assessed, and;

${ }^{16} \mathrm{Id}$.

${ }^{17} \mathrm{Id}$.

${ }^{18} \mathrm{Id}$.

${ }^{19} I d$. at 362; $c f$. ELAINE RiCH ET AL., ARTIFICIAL INTELLIGENCE 3 (3rd ed. 2009) (defining AI as "the study of how to make computers do things which, at the moment, people do better").

${ }^{20}$ Scherer, supra note 15 , at 362.

21 See, e.g., Turing, supra note 8. 
(iii) computers would be capable of learning independently. ${ }^{22}$ After him, many AI techniques have been improved by pushing the borders of these questions. ${ }^{23}$

The complex nature of intelligence itself engages various fields of inquiry - including psychology, neuroscience, engineering, linguistics, and the like - and AI researchers have benefited greatly by drawing on insights from them. ${ }^{24}$ Many factors have contributed to the development of the AI revolution over the past quarter century. ${ }^{25}$ One of the significant breakthroughs was experimental achievements in artificial neural networks. Thanks to advances in cloud computing and online data collecting, machine learning has blossomed. ${ }^{26}$ More importantly, the development of "deep learning," which is a type of artificial neural network produced through "backpropagation,"27 has produced dramatic improvements in $\mathrm{AI}^{28}$ The rise of the internet enabled researchers to assemble huge databases, paving the way for the employment of statistical methods to seek and analyze patterns in the vast amounts of data stored therein. ${ }^{29}$ In the future, the need for human training of neural networks is likely to attenuate as AI becomes autodidactic. Techniques such as unsupervised training of deep neural networks that teach machines to detect connections amongst enormous data irrespective of defined rules by a human operator herald such a shift. ${ }^{30}$ These advances have already profoundly affected society in many ways - think of autonomous cars, drones, and robot warriors. Such advances have also resulted in the birth of highly creative

22 See id.

${ }^{23}$ For example, the structure of artificial neural networks was first introduced by Rosenblatt's Perceptron as a computational model inspired by biological neuron model. See, e.g., Frank Rosenblatt, The Perceptron-A Perceiving And RECOGNIZING AUTOMATON: REPORT 85-460-1 (1957).

${ }^{24}$ For instance, artificial neural networks were stimulated by the movement of information in biological neurons. See, e.g., David Silver et al., Mastering the Game of Go with Deep Neural Networks and Tree Search, 529 NATURE 484 (2016).

${ }^{25}$ Peter Stone et al., Artificial Intelligence and Life in 2030: One Hundred Year Study on Artificial Intelligence: Report of the 2015-2016 Study Panel, STAN. U.

(Sep. 12, 2016), https://ai100.stanford.edu/2016-report.

${ }^{26} \mathrm{Id}$.

${ }^{27}$ Backpropagation is a technique deployed in artificial neural networks to estimate a gradient which is required for the computation of weights to be deployed. See Backpropagation, AM. HeRITAGE DictionaRY OF THE ENG. LANGUAGE, (5th ed., 2019).

${ }^{28}$ Peter Stone et al., Artificial Intelligence and Life in 2030: One Hundred Year Study on Artificial Intelligence: Report of the 2015-2016 Study Panel, STAN. U. (Sep. 12, 2016), https://ai100.stanford.edu/2016-report.

${ }^{29} \mathrm{Id}$.

${ }^{30}$ Yann LeCun et al., Deep Learning, 521 NATURE 436, 439 (2015). 
machines which is the subject of this note. For example, the computer program Iamus composes music by transforming basic preliminary material in a manner akin to biological evolution, whereby a musical core called a "genome" becomes iteratively more complex over time. ${ }^{31}$ Machines are composing and conducting musical theatre pieces where algorithms analyze and reunite the song on which the singers can follow screens. $^{32}$ Watson, a computer designed by IBM for the express purpose of decoding and answering complex questions, defeated the champion Ken Jennings in a match-up on the TV-quiz show "Jeopardy!." Jennings had previously beaten human contestants on Jeopardy! on seventy-four occasions. ${ }^{33}$ The Google-backed project, Magenta, aims to teach machines specific behaviors by utilizing deep neural networks to analyze "big data," and eventually to compose music or generate artwork, such as sketches, videos, and jokes. ${ }^{34}$ A different team at Google has developed software called DeepDream, which employs neural networks to generate psychedelic paintings. ${ }^{35}$ A short sci-fi movie, Sunspring, was written by an artificial neural network, which named itself "Benjamin." 36 A new "Rembrandt" painting was created by $\mathrm{AI}$, based on its learning of the artist's signature style in a collaborative project named "The Next Rembrandt." 37 As illustrated above, these examples bring forth a novel issue: are AI-generated works copyrightable? The next section will address this question.

${ }^{31}$ Philip Ball, Iamus, Classical Music's Computer Composer, Live from Malaga, GUARDIAN (Jul. 1, 2012),

https://www.theguardian.com/music/2012/jul/01/iamus-computer-composesclassical-music.

${ }^{32}$ Charles Isherwood, Review: 'Yesterday Tomorrow' a Meeting of Songs About Time, N.Y. TIMES (Jan. 14, 2016),

https://www.nytimes.com/2016/01/15/theater/review-yesterday-tomorrow-ameeting-of-songs-about-time.html.

33 John Markoff, Computer Wins on 'Jeopardy!': Trivial, it's Not, N.Y. TIMES (Feb. 16, 2011), https://www.nytimes.com/2011/02/17/science/17jeopardywatson.html.

${ }^{34}$ Cade Metz, How A.I. Is Creating Building Blocks to Reshape Music and Art, N.Y. Times (Aug. 14, 2017),

https://www.nytimes.com/2017/08/14/arts/design/google-how-ai-creates-new-musicand-new-artists-project-magenta.html.

${ }^{35}$ Alexander Mordvintsev et al., Inceptionism: Going Deeper into Neural Networks, GoOGLE AI BLOG (Jun. 17, 2015),

https://ai.googleblog.com/2015/06/inceptionism-going-deeper-into-neural.html.

${ }^{36}$ Annalee Newitz, Movie Written by Algorithm Turns Out to be Hilarious and Intense, ARsTECHNICA (June 9, 2016), https://arstechnica.com/gaming/2016/06/anai-wrote-this-movie-and-its-strangely-moving/.

${ }^{37}$ See The Next Rembrandt, https://www.nextrembrandt.com, ING (last visited Mar. 15, 2019). 


\section{ARE AI-GENERATED WORKS ELIGIBLE FOR COPYRIGHT PROTECTION?}

\section{A. A Fixed Intangible Medium of Expression}

According to the Copyright Act of 1976 ("the Act"), copyright exists in an author's original work, so long as it is fixed in a tangible medium of expression that can be observed, duplicated, or communicated, either directly or with the employment of a machine or device currently known or subsequently developed. ${ }^{38}$ "Fixedness" is defined under the Act whereby embodiment in a copy is sufficiently stable to enable someone to perceive, duplicate, or communicate the work for an extended period; momentary or temporary embodiment is thus excluded..$^{39}$ Legislative history has clarified that Congress' intention was to encompass all forms or modes of fixation: notes, numbers, sounds, pictures, graphic, or symbolic indicia, embodied in a physical object in written, printed, photographic, sculptural, magnetic, or any other stable form. ${ }^{40}$ The capabilities of AI systems easily qualify under this requirement, as indicated by the "Next Rembrandt" paintings and other examples given in the previous chapter.

\section{B. Creativity}

\section{Creativity Standards: Feist}

In Feist Publ'ns, Inc. v. Rural Tel. Serv. Co., the Supreme Court held that a minimal level of creativity must be contained in a copyrightable work; it did not, however, offer a comprehensive definition of creativity. ${ }^{41}$ In setting this minimal threshold for creativity, the court set the bar extremely low; even a slight quantity of creativity is sufficient for copyright protection. ${ }^{42}$ The overwhelming majority of works will pass the copyright-eligibility test easily, the court stated, since they contain some "creative spark" regardless of how basic, modest, or plain it might be. ${ }^{43}$ Theoretically, creative inquiry requires an objective assessment of the content of the work in question based on artistic foresight or choice of earlier materials by taking the specific

\footnotetext{
${ }^{38}$ See 17 U.S.C.A. $\$ 102(a)$.

${ }^{39}$ Id. $\S 101$.

${ }^{40}$ H.R. REP. No. 94-476, at 52 (1976).

${ }^{41}$ Feist, 499 U.S. at 345.

${ }^{42}$ See id.

${ }^{43}$ See id.
} 
subject matter into account. ${ }^{44}$ Creativity particularly focuses on "the distinctiveness of copyrightable expression" rather than the inventive step or the newness of an idea. ${ }^{45}$ Most importantly, American courts emphasized that the copyright act is aimed to protect "human creativity." 46

\section{Tracing the Locus of Difference Between Human and Computational Creativity}

One could ask what the difference between human and computational creativity is. Indeed, the question has prompted furious philosophical debate in the decades since computer technology emerged. ${ }^{47}$ To begin, the meaning of "creativity" demands a definition. There is an almost consensual definition of creativity in which an output

${ }^{44}$ Wiliam F. PATRY, PATRY ON COPYRIGHT, $\$ 3: 31$ (rev. ed. 2019) (offering two great examples: one can create from the scratch an unoriginal work but lacks the creativity, and another could have built his or her ideas from prior works but synthesized those concepts with creative expression.); see also, Bleistein v. Donaldson Lithographing Co., 188 U.S. 239, 251-52 (1903) (holding that judges, who are only competent at law, should not be considered as the final arbiters of the aesthetic merits of graphical representations because some works would not be appreciated sufficiently enough by the public because it is ahead of its time. Conversely, copyright would not be granted to pictures appreciated by the public who is less educated than the judge).

${ }^{45}$ Melville B. Nimmer \& DAVId Nimmer, Nimmer ON COPYRIGHT, $§ 2.01$ [B][2] (rev. ed. 2018) (referencing some cases where copyright protection was rejected for non-creative variants of musical compositions, randomly produced numbers or types of expressions generated by functional thoughts).

${ }^{46}$ Urantia Foundation v. Maaherra, 114 F.3d 955, 958 (1997) (" $[\mathrm{I}] \mathrm{t}$ is not creations of divine beings that the copyright laws were intended to protect, ... some element of human creativity must have occurred in order for the Book to be copyrightable."); Whelan Associates, Inc. v. Jaslow Dental Laboratory, Inc., 797 F.2d 1222, 1229 (1986) ("[A]lgorithms must be developed by the human creativity of the programmer ..."); Sprint Corp. v. Commissioner, 108 T.C. 384, 406 (1997) ("As the result of human creativity and design, copyright or patent protection is available for it."); Canatelo, LLC v. TRENDnet, Inc., Not Reported in F.Supp.3d, 1, 7 (2015) ("This court values the importance of continued innovation that naturally comes from human creativity and ingenuity. This court will therefore not restrict patentee's rightful claim ... "); DaVinci Editrice S.R.L. v. ZiKo Games, LLC, Not Reported in F.Supp.3d, 1 (2014) ("Human creativity takes many forms. Devising games for people to play, including card games, is one of them.... [T]he plaintiff. . . alleges that the defendants . . infringed the copyright . . in a card game ...").

${ }^{47}$ See Emerging Technology from the arXiv, The Secret Ingredient in Computational Creativity, MASs. Inst. OF TECH. (Nov. 11, 2013), https://www.technologyreview.com/s/521596/the-secret-ingredient-incomputational-creativity/. 
must satisfy two requisites. ${ }^{48}$ First, it must be novel. ${ }^{49}$ Second, it has to possess value, as novelty alone might prove worthless in some circumstances. ${ }^{50}$ In this vein, Margaret Boden, a pioneering researcher on computational creativity, defines creativity as the ability to produce "novel, and valuable, ideas." 51 She finds that a novel idea has two dimensions: (i) psychological novelty (P-creativity), whereby the idea is new to the person who is the originator of that idea, ${ }^{52}$ and; (ii) historical novelty (H-creativity), whereby the idea is new to the world (but also encompasses P-creativity). ${ }^{53}$ As for the former, the fact that others may have generated the same idea before is irrelevant. ${ }^{54}$ For $\mathrm{H}-$ creativity, we are speaking of the more "glamorous" notion; an original idea in the classic sense..$^{55}$

Annemarie Bridy rightly connects Boden's binary theory to existing intellectual property standards and suggested that P-creativity is consistent with originality standards in copyright law, since it is only related to the novelty of the idea to the person rather than to society or history. ${ }^{56}$ A work is still accepted as original even though the work was created earlier by someone else, provided that it is not a copy of that prior work. ${ }^{57}$ Boden contends that computers can even reach $\mathrm{H}$ creativity, as many examples of artificially intelligent inventions and creations already exist. ${ }^{58} \mathrm{~A}$ three-dimensional silicon chip, invented by a machine, was granted a patent. ${ }^{59}$ A tiny antenna invented by evolutionary software has been employed in space missions by NASA. ${ }^{60}$ John Koza's Genetic Programming was deployed to dream

${ }^{48}$ See Dean Keith Simonton, Defining Creativity: Don't We Also Need to Define What Is Not Creative?, J. OF CREATIVE BEHAV. 1, 2 (2016).

${ }^{49} \mathrm{Id}$.

${ }^{50}$ Elliot S. Paul \& Scott B. Kaufman, The PhILosophy OF CREATIVITY 1, 6 (2014).

${ }^{51}$ Margaret A. Boden, Computer Models of Creativity, 30 AI MAG. 23, 24 (2009) (defining "valuable" something equal to "interesting, useful, beautiful, simple, richly complex, and so on" whereas "ideas" encompasses not only "concepts, theories, interpretations, stories" but also "artefacts", including "graphic images, sculptures, houses, and jet engines").

${ }^{52} I d$. at 24.

${ }^{53} \mathrm{Id}$.

${ }^{54} I d$.

${ }^{55}$ Margaret A. Boden, The Philosophy of Creativity 224, 228 (2014)

(considering H-creativity to be the bedrock of creativity).

${ }^{56}$ Annemarie Bridy, Coding Creativity: Copyright and the Artificially

Intelligent Author, 2012 STAN. TECH. L. REV. 5,17 (2012).

${ }^{57} \mathrm{Id}$. at 13.

${ }^{58}$ Boden, supra note 51, at 24.

${ }^{59} I d$.

${ }^{60}$ Robert Plotkin, The Genie in the Machine: How ComputerAutomated INVENTING is REVOLUTIONIZING LAW AND Business 1 (2009) (also 
up a novel controller which was later patented along with the computerautomated method. ${ }^{61}$ These examples indicate that computers can achieve H-creativity.

Boden further explains the formation of creativity in three particular ways: (i) combinational creativity, reflecting the novel combination of well-known ideas, usually arising from making connections between ideas that were formerly only obliquely related; ${ }^{62}$ (ii) exploratory creativity based on culturally recognized types of thinking or "conceptual space" that is delineated by a group of productive rules, ${ }^{63}$ and; (iii) transformational creativity, where the conceptual space or style is reconstructed by changing one or more characteristic features, allowing space for new ideas that could not have been accommodated before the change. ${ }^{64}$
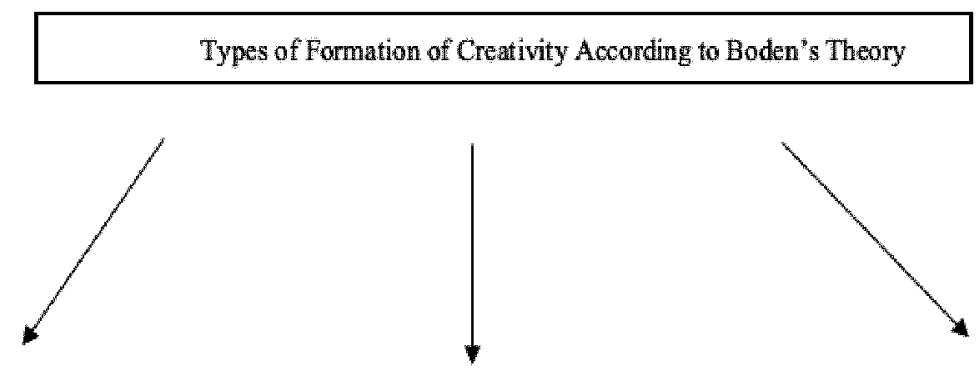

1) Combinational Creativity - Arises from the novel combination of existing ideas

- These ideas are prewously unrelated.
2) Explonatory Creativity

- Hinges on culturally accepted types of thinking or conceptual space which is described by a set of productive rules that are usually almost precise.
3) Transfomational Creativity - Follows a drastic change in conceptual space or style.

- New concepts, which could net have been possible before the change, from in this novel space.

claiming that no human engineer would have come up with an antenna that looked weird, but the antenna performs efficiently than formerly human designs).

${ }^{61} I d$. (referring to U.S. Patent No. 6,847,851 and U.S. Patent No. 7,117,186).

${ }^{62}$ Boden, supra note 51, at 24 (demonstrating that this type of creativity is exemplified by poetic imagery or collage, as well as science, e.g. the BohrRutherford solar system model inspired by the atom).

${ }^{63} \mathrm{Id}$. at 25 (asserting that these rules are almost completely or wholly certain, and the examples of exploratory creativity would be a theory of chemical molecules, a painting style).

${ }^{64} \mathrm{Id}$. (expressing that the history of science and art is full of sad examples, like Vincent Van Gogh, who only sold one painting during his life). 
Selmer Bringsjord and David Ferrucci contend that computers are more likely to achieve combinational creativity than exploratory and transformational creativity on account of their lack of autonomy. ${ }^{65}$ Yet, Boden argues that contrary to common belief, combinational creativity is the most difficult form for AI models since no existing AI model can acquire the vast and subtly related set of concepts that an ordinary human develops during his or her lifetime. ${ }^{66}$ Exploratory creativity, however, might actually prove easier for AI than combinational creativity. This could be achieved by subtly integrating the rules of pertinent thinking style into the computer program, but only if the human programmer creating this capability had AI skills as well as technical proficiency in the related domain. ${ }^{67}$ Transformational creativity pursues diligent investigation, which leads to transformation once the initiator changes formerly established restraints or simply brings one or more novel restraints. ${ }^{68}$

Some skeptics argue that even if computers go beyond human intelligence, none could be considered truly creative. Creativity, they contend, belongs instead to the original programmer. ${ }^{69}$ "Creative computer" is, in this view, a contradiction in terms, since it is unfeasible in practice. ${ }^{70}$ Those who stand against the view argue the following: (i) some particular features that computers have preclude them from acquiring creativity, they are simply following the program $;{ }^{71}$ (ii) computers do not have specific features that their human counterparts naturally possess, for instance, consciousness. ${ }^{72}$ Boden responds to the

${ }^{65}$ Selmer Bringsjord \& David Ferrucci, Artificial Intelligence and Literary Creativity: Inside the Mind of Brutus, A Storytelling Machine, at xix (2000).

${ }^{66}$ Boden, supra note 51, at 25-26 (leaving the door open to creating an AI model that generates combinations as linguistically and culturally responsive as individuals do, while noting this is an extremely difficult task at present).

${ }^{67} \mathrm{Id}$. at 27.

${ }^{68}$ Boden, supra note 55, at 228.

${ }^{69} \mathrm{Id}$. at 224.

${ }^{70} \mathrm{Id}$.

${ }^{71}$ Selmer Bringsjord et al., Creativity, the Turing Test, and the (Better) Lovelace Test, 11 Minds \& MACHINES 3, 3-4 (2011) (arguing that computers are not capable of creating because the ability to create is equivalent to originating something, which is absent in computers that simply follow the orders given by a program).

72 The opposition arguments mostly rely on John Searle's thought experiment in which a person who cannot speak any Chinese is locked in a room with a bunch of Chinese letter-symbols (characters). She also has a set of rules, written in English, like a code book ("the program"), that allow her to provide the 'appropriate' response to any Chinese scripts she may come across. These rules enable her to connect one group of formal rules to another group of formal rules. The formality of rules means that their application can be achieved purely via visual connections. Next, a question script, in Chinese, is slipped through the door of the room asking her, in Chinese, "Do you speak Chinese?" She is able to use the program to 
second criticism on the ground that it ignores the fact that a program may incorporate rules "for changing itself," e.g. genetic algorithms that may make haphazard alterations in previously-defined rules. ${ }^{73}$ The computer program is capable of learning, based on unforeseen input from the environment, or owing to the control it exerts over its own experimentation. ${ }^{74}$

Some skeptics take the position that even advanced programs are primarily confined to the possibilities already established in rules implemented by the original programmer. ${ }^{75}$ They claim that authentic, drastic transformations can only occur in a developing system in which it engages in physical interaction with genuine processes in the world. ${ }^{76}$ Boden's counterargument is that those skeptics treat AI as either a simulation or as abstract programming that delineates the interactions that can arise between program and world. ${ }^{77}$ This, however, is not evidently true for all AI systems since recent studies have already produced a sensor that evolves in its environment, a process that to date was only thought possible under conditions of natural biology. ${ }^{78}$

Another objection would come from the argument that sees the human brain as a "meat machine," a term coined by MIT's Marvin Minsky. ${ }^{79}$ This idea is that the human brain is an electrical and chemical mechanism: (i) the organization of which is immensely sophisticated;

determine the "correct" response, "No I do not," and then select from her jumble of Chinese characters the right order of specific Chinese symbols with particular types of shapes that match to send her "answer"-which of course she does not "understand"- back through the door. With practice, as the program becomes more familiar to her over time, she will become so adept at "communicating" in Chinese in this way that her answers to the questions will eventually become indistinguishable from that of a native Chinese speaker. All the while, she has not learned a single word of Chinese. She has merely performed computational activities and cannot speak - or understand - the language in which she is "communicating". The experiment intends to demonstrate that computers merely apply rules, however complex, and nothing more. John R. Searle, Minds, Brains, and Programs, 3 BEHAV. \& BRAIN SCI. 417, 419-23 (1980).

${ }^{73}$ Boden, supra note 51, at 29 (comparing these alterations to the point mutations and crossovers that govern biological evolution, and stating that other advanced programs may also include a "fitness" function that chooses each new generation of task programs to use them as parents in subsequent random rule altering.).

${ }^{74}$ Boden, supra note 55, at 230.

${ }^{75}$ Lance Whitney, Are Computers Already Smarter Than Humans?, TIME (Sep.

29, 2017), https://time.com/4960778/computers-smarter-than-humans/.

${ }^{76}$ Boden, supra note 55, at 230.

${ }^{77} \mathrm{Id}$. at 225 .

${ }^{78} \mathrm{Id}$. at 231.

${ }^{79}$ Id. at 238 . 
(ii) the evolution of which is scarcely comprehended, and; (iii) that generates complicated behavior in response to environmental stimuli. ${ }^{80}$

The claim that computers cannot possess the same features that humans naturally possess focuses particularly on three core factors: autonomy, intentionality, and consciousness. ${ }^{81}$ Since autonomy means that the ideas are "freely" produced, Boden argues that H-creativityand, for the most part, P-creativity - is autonomous on the basis that it is allowed by partly distinctive personal experience, and partly by the human brain, which is itself a gift of evolution. ${ }^{82}$ Boden asserts that if we accept the strict definition of autonomy, then computers could not ever be creative, as no programmed entity could be truly autonomous. ${ }^{83}$ This is consistent with the state of the art of AI technology since there is no example of fully autonomous AI that acts freely, represents itself, sues in court, or enters into contractual restraint. ${ }^{84}$ Computer scientists divide AI into different categories based on the level of intelligence, e.g., human-level intelligence or general intelligence ("AGI"), ${ }^{85}$ or superintelligence-intelligence beyond human-level AGI. ${ }^{86}$ Ray Kurzweil, a prominent computer scientist and inventor, predicts that computers will reach human-level AGI in $2029,{ }^{87}$ yet surveys conducted

${ }^{80}$ PAMELA MCCORduck, Machines Who Think: A PERsonal INQUiRy into

THE HISTORY AND PROSPECTS OF ARTIFICIAL INTELLIGENCE 85-86 (1979).

${ }^{81}$ Boden, supra note 55, at 224.

${ }^{82} \mathrm{Id}$. at 233. (emphasizing that autonomy, or self-direction, is inherent in the very act of originating or developing a concept.)

${ }^{83} \mathrm{Id}$. at 242.

${ }^{84}$ See, e.g., Ryan Calo, Robotics and the Lessons of Cyberlaw, 103 CALIF. L. REV. 513, 528 (2015) ("[V]arious authors have imagined a world in which robots or software achieve, or at any rate claim, a human-like consciousness. Little in the literature gives me confidence that artificial intelligence will approximate human intelligence in the foreseeable future. There are analytic and technical reasons to believe robots will never think like people.") (internal citations omitted); HANNAH YeEFen Lim, Autonomous Vehicles And the LAW: TeCHNOLOGY, Algorithms AND ETHICS 1 (2018) ("The artificial intelligence technology appears intelligent but in reality is without intelligence ... . [T] he technology is very much explainable in terms of computer science and mathematics. Contrary to what many people believe, there is no real intelligence... behind artificial intelligence.").

${ }^{85}$ Sam S. Adams et al., Mapping the Landscape of Human-Level Artificial General Intelligence, 33 AI MAGAZINE 25, 26 (2012) ("[T]he goal of AGI research . . . is the development and demonstration of systems that exhibit the broad range of general intelligence found in humans.").

${ }^{86}$ Nick Bostrom, SuPERINTElligence: PAths, Dangers, Strategies 22 (2014) (defining superintelligence as "any intellect that greatly exceeds the cognitive performance of humans in virtually all domains of interest.").

${ }^{87}$ John Tierney, The Future Is Now? Pretty Soon, at Least, N.Y. TIMES, (June 3, 2008), https://www.nytimes.com/2008/06/03/science/03tier.html ("By 2029, Dr.

Kurzweil wagers, a computer will pass the Turing Test by carrying on a conversation that is indistinguishable from a human's."). 
with other prominent scholars reveal that the aim of building AI which can perform all aspects of human-level intelligence is not expected to become reality in the foreseeable future. ${ }^{88}$ Even if we assume that human-level AGI can be achieved, whether or not it will be formed as human-like physical embodiment is also not clear. Since the AI has not possessed all features of humans yet, and there is still a long way to acquire those skills, the autonomy requisite is the most significant obstacle to machine creativity which could only be overcome by the existence of humans before or after the creative process. ${ }^{89}$

${ }^{88}$ A recent survey was carried out with 170 prominent AI researchers around the world. One of the questions posed in the survey was that "by what year would you see a $(10 \%-50 \%-90 \%)$ probability for such HLMI to exist?” HLMI stands for high-level machine intelligence that can perform most human professions at least as well as an ordinary human. This is highly likely to fall within the standard of Turing test. The median estimate of when there will be $50 \%$ probability for such HLMI to exist was 2040 , whereas the median estimate of $90 \%$ probability was 2090 . Vincent C. Müller \& Nick Bostrom, Future Progress in Artificial Intelligence: A Survey of Expert Opinion, in Fundament aL IsSUES OF ARTIFICIAL INTELLIGENCE 555-572 (Vincent C. Müller ed., 2016). One of the earliest surveys about the future of AI was recorded live during the 2006 Al@, 50 conference -where all participants of the 1956 Dartmouth College were present- via a wireless voting device. The results were not published, yet Müller and Bostrom obtained these results from the organizers.

According to this survey, 41 percent of participants responded that the machines will be able to stimulate all aspects of human intelligence after more than fifty years, and 41 percent of participants reacted that machines will never able to do that. Id. In another survey, participants were asked this question: "assuming no global catastrophe halts progress, by what year would you assign a $10 \%-50 \%-90 \%$ chance of the development of human-level machine intelligence?" The median estimate of when there will be $50 \%$ chance of human-level machine intelligence was 2050. Anders Sandberg \& Nick Bostrom, Machine Intelligence Survey, FHI TECH. REPORT 1, 1 (2011), https://www.fhi.ox.ac.uk/wp-content/uploads/2011-1.pdf. According to another survey, there is a clear dichotomy between AI-optimists and techno-skeptics. 38 percent of twenty-one participants with significant background in AI thought that AI will pass Turing test in the period after 2030 and 19 percent opted that AI will pass the test after 2090 or never be able to accomplish, whereas 42 percent of participants think that AI will pass Turing test either in 2010s or in 2020s. Seth D. Baum et. al., How Long Until Human-level AI? Results From an Expert Assessment, 78 Tech. Forecasting \& Soc. Change 185, 188-89 (2011); MaX Tegmark, Life 3.0 - Being Human in the Age of Artificial INTElligence 32-3 (2017) ("Another prominent group of thinkers aren't worried about AI either . . they think that building super-human AGI is so hard that it won't happen for hundreds of years ... Most of the utopians think human-level AGI might happen within the next twenty to a hundred years, which the techno-skeptics dismiss ass uninformed pie-in-the-sky-dreaming, often deriding the prophesied singularity as 'the rapture of the geeks."').

${ }^{89}$ See Paul Thagard, How Does Current AI Stack Up Against Human

Intelligence, Psychology TODAY (Nov. 12, 2018),

https://www.psychologytoday.com/us/blog/hot-thought/201811/how-does-currentai-stack-against-human-intelligence. 
As for consciousness and intentionality, things are not so straightforward. Boden argues that it has been known for a long time that creative ideas are frequently produced without consciousness. ${ }^{90}$ They may emerge unexpectedly during artistic creation, problemsolving, incubation, thinking about completely different things or even while sleeping, without the originator being able to explain quite how the idea was born. ${ }^{91}$ The reason why people assume consciousness as an essence of creativity is because creative activities are consciously observed and characteristically include conscious evaluation. ${ }^{92}$ This evaluation is strictly tied to social acceptance, particularly in art and fashion, and neglects the fact that computers will reach P-creativity or H-creativity. ${ }^{93}$ Although creativity in art is often correlated to intense subjective emotions, ${ }^{94}$ and may be what drives both scientists and artists, emotions should not be considered a conscious feeling, as emotions contain sophisticated mechanisms deeply rooted in one's mental structure and are necessary if sophisticated multi-motivated creatures are to arrange activities. ${ }^{95}$

Regarding intentionality, Boden rejects the Surrealists' argument that automatic writings as unintentional artifacts on the ground that they in fact emanate from intentional, albeit involuntary, processes. ${ }^{96}$ Although some dimensions of consciousness, such as emotions of anxiety or grief, are claimed to be explained by computational terms by Aaron Sloman, ${ }^{97}$ Boden asserts that he himself relies on superficial

${ }^{90}$ Boden, supra note 55, at 234.

${ }^{91} \mathrm{Id}$. (For example, Surrealists propose that consciousness is not an essence of creativity. Plus, creative ideas, such as we see in daily conversation, are always produced without 'full consciousness' of the underlying process producing them).

${ }^{92} \mathrm{Id}$. at 235.

${ }^{93}$ Boden, supra note 51 , at 30 .

${ }^{94}$ Maria Popova, What Freud Said About Writing Fiction, The AtLanTIC (Oct. 16, 2012), https://www.theatlantic.com/entertainment/archive/2012/10/what-freudsaid-about-writing-fiction/263623/ ("[The creative writer] creates a world of phantasy which he takes very seriously - that is, which he invests with large amounts of emotion - while separating it sharply from reality.") (emphasis added).

${ }^{95}$ Boden, supra note 55, at 235.

${ }^{96} \mathrm{Id}$. at 234.

${ }^{97}$ Aaron Sloman, An Alternative to Working on Machine Consciousness, 2 INT'L J. MACHINE CONSCIOUSNESS 1, 13 (2010) ("[I] have explored the idea of a disembodied mathematician concerned only with finding interesting, new, increasingly complex mathematical conjectures, seeking proofs or refutations, trying to improve on old proofs, becoming excited when a problem looks close to being solved, anxious when a proof begins to look flawed, relieved when the flaw is removed, delighted when a very hard problem is finally solved, and so on ... [I] see nothing inconsistent in the possibility of such a disembodied system ... A disembodied artificial mathematician of that sort might never experience colours, toothache, the effort walking uphill, the resistance to pushing a large object, and so 
psychological theories, and takes for granted that emotion must produce behavioral effects, which in fact may last without any such effect. ${ }^{98}$

In sum, there is no still consensus amongst computer scientists, cognitive scientists, naturalists, or philosophers on what the role of consciousness, emotion, and intention is in the creative process and whether a computer could possess those features. Boden concludes that the question of whether a computer could ever truly be creative cannot presently be answered since it brings a highly furious debate to the forefront. ${ }^{99}$ The question of whether computers really are creative, in other words, is not a scientific one, but rather a philosophical one. ${ }^{100}$

\section{A Reasonable Pathway}

Fortunately, our inability to definitively answer whether a computer could ever "truly" be creative does not preclude investigation of the copyrightability of AI-generated works. Whether or not computers have the ability that humans possess should not be confused with the key question of whether computers can generate copyrightable work irrespective of differences between computers and humans. The previous subsection focuses on the philosophical debate, which informs us what computer lack that human possesses in creativity process.

Robert Plotkin argues that since computers do not create a work ex nihilo, and therefore still in some respects need human guidance, that humans will continue to play an important role in the foreseeable future. ${ }^{101}$ This of course does not undercut the computer's role in the process, as it is plain that the performance of a computer may be truly independent. ${ }^{102}$ However, since computers lack autonomy, this leads us to the conclusion that we should instead focus on the human who guides the computer and the creative process with which it is associated.

For the sake of copyright purposes, an objective approach, which essentially takes "a work" into consideration, should be followed.

on, but it would experience equations, geometric and other structures, a proof being nearly complete, and so on ... Of course, without a body it will not have any feelings in its stomach, tingling of skin, inclinations to jump for joy. But those are unnecessary for the emotions associated with doing mathematics.") (emphasis added).

${ }_{98}$ Boden, supra note 55, at 240.

${ }^{99} \mathrm{Id}$. at 242.

${ }^{100}$ Boden, supra note 51, at 33.

${ }^{101}$ Plotkin, supra note 60 , at 4.

102 See, e.g., Mark Coeckelbergh, Can Machine Create Art?, 30 PHIL. TECH. 285,286 (2017) (" $[\mathrm{T}]$ he algorithm, the code, is programmed, but the end productwhat is claimed to be the work of art-is not directly made by a human being. The algorithm, not the human, is the "artistic" agent."). 
Boden proposes a very practical test for assessing machine creativity, one that modifies Turing's test. ${ }^{103}$ For Boden, a specific computer program should be accepted as "artistic" if: (i) the program's output cannot be differentiated from the work of a human and; (ii) the work's aesthetic value could be judged equal to the work of a similar nature created by a human. ${ }^{104}$ This second criterion could be investigated by comparing average human art, or it could compare to first-class examples. ${ }^{105}$

Specifically, Boden asserts that programs like AARON would easily satisfy the test. ${ }^{106}$ AARON can draw beautiful paintings. It was designed by Harold Cohen-a pioneer researcher in algorithmic artand many creations generated by AARON have been exhibited at museums around the world. ${ }^{107}$ The criterion of comparison with average human art is also consistent with the Feist criteria for creativity, which only requires a basic, modest, or plain creative spark. ${ }^{108}$ This approach, therefore, does not dig into the philosophical debate on creativity and it offers more efficient solution regarding AI-generated work.

\section{Originality}

\section{The Constitutional and Statutory Grounds}

Copyright protection in the United States relies on the United States Constitution which empowers Congress to "secure for limited Times to Authors . . . the exclusive Right to their respective writings." 109 According to the Court in The Trademark Cases, the term "writings" encompasses works only if they are original and are generated by "the creative powers of the mind." 110 The Court expressly stated that only writings which are "the fruits of intellectual labor" are covered by copyright protection, the latter condition hinging upon some "work of

${ }^{103}$ Margaret A. Boden, The Turing Test and Artistic Creativity, 39

KYBERNETES 409, 409 (2010).

${ }^{104} \mathrm{Id}$.

${ }^{105} I d$. at 412 .

${ }^{106} \mathrm{Id}$. at 412.

${ }^{107}$ Chris Garcia, Harold Cohen and AARON-A 40-Year Celebration, COMPUTER History Museum (Aug. 23, 2016),

https://www.computerhistory.org/atchm/harold-cohen-and-aaron-a-40-yearcollaboration/.

${ }^{108}$ Feist, 499 U.S. at 345.

${ }^{109}$ U.S. CONST. art. I, $\S 8$, cl. 8.

${ }^{110}$ In re Trade-Mark Cases, 100 U.S. 82, 94 (1879). 
the brain."111 In Burrow-Giles, the Court defined an author as one "who is at the origin of something," the originator or creator; the one who finishes a work of science or literature. ${ }^{112}$

Section 102(a) of the Act expressly states that copyright protection extends to original works of authorship. ${ }^{113}$ There is no definition of "original works of authorship" under the Act. Yet, the legislative history of the Act proves that the term was intentionally left undefined in order to consistently maintain the standard of originality applied by the courts. ${ }^{114}$ In Feist, a landmark case, the Court held that the touchstone of copyright is originality, which means that a work must be original to the author. ${ }^{115}$ The Court defined originality in two steps: (i) the work was independently created by the author rather than copied from prior works; and (ii) the work contains a minimum degree of creativity. ${ }^{116}$ According to the Court, the originality requirement does not equate to novelty. A work may therefore be considered as original even if there is a strong resemblance with existing works, provided that the resemblance is coincidental and not the consequence of copying. ${ }^{117}$ There is no correlation between independent creation and creativity which should be considered as separate requirements. ${ }^{118}$ As for the originality, the fact that the plaintiff did not merely copy from another

\footnotetext{
${ }^{111} I d$.

${ }^{112}$ Burrow-Giles Lithographic Co. v. Sarony, 111 U.S. 53, 58 (1884) (citing Worcester's Dictionary (1860)).

11317 U.S.C.A. $\$ 102$ (a) (West 2016).

${ }^{114}$ H.R. REP. No. 94-1476, at 51 (The House Report reveals that this standard does exclude the prerequisites of novelty, ingenuity and aesthetic merit. Moreover, the language of "original works of authorship" was intended to avoid exhausting the constitutional and legislative power of Congress in the field. The other objective of the House Report is to keep up with scientific discoveries and technological developments which enabled new forms of copyrightable subject matter-electronic music, film-strips, or computer programs - that Congress were willing to protect and deemed to be copyrightable without a legislation. However, the House Report makes it clear that if the forms of expression had existed for a long time but have been recently accepted as a worthy of protection, then a specific statutory recognition is required for such expression - photographs, sound recordings, motion pictures, music, drama, and works of art. Although an AI-generated work could be considered as a new form of expression and fall within the former, the lack of human author during a creative process would make the Congress's intention unpredictable).

${ }^{115}$ Feist, 499 U.S. at 345-47.

${ }^{116} I d$. at 345 (citing Nimmer \& Nimmer, supra note 45, § 2.01).

${ }^{117} \mathrm{Id}$. (The Court gave an example where two poets who do not know each other write identical poems. Both works are original and copyrightable, but not novel).

${ }^{118}$ Nimmer \& Nimmer, supra note 45.
} 
sufficed. ${ }^{119}$

\section{The Development of Case Law}

Although there has so far been no specific case in the United States that directly addresses the issue of originality of AI-generated work, the possible reactions could be derived from mechanical process, animal authorship, and psychic cases, which will be investigated in turn through the current section.

As for cases related to mechanical process, in Southco Inc v. Kanebridge Corp., where the alleged infringement was the defendant's reference to the serial numbers that the plaintiff attaches to its goods, the Third Circuit held that those numbers are the product of a mechanical process deployed by the inflexible rules of the system and are therefore not original. ${ }^{120}$ If the same logic applies to AI-generated work, the Courts are likely to exclude them from copyrightability due to not being original.

Interestingly, Bridy finds a correlation between psychedelic works and AI-generated works. ${ }^{121}$ In Urantia Foundation v. Maaherra, both the plaintiff and the defendant agreed that the words in the work in question, the Urantia Book, were in fact authored by non-human celestial entities via the unnamed patient of psychiatrist Dr. William Sadler. ${ }^{122}$ The defendant claimed that there is no copyright on the book due to the lack of human origin, wherein the Court pinned that the group, formed by Dr. Sadler to prepare questions to be asked for celestial entities via the patient and discuss the work authored by those entities, subsequently selected and carefully prepared to be asked, considerably helped to the structure of the work, planned the disclosure in the work, decided the order of the work. ${ }^{123}$ The court held that this selection and arrangement of the work met a low threshold of creativity, as it was not a mechanical or a routine activity. ${ }^{124}$

The District Court in Urantia Foundation, however, interpreted the creations of celestial beings differently. The Court simply stated that the Urantia Book is a literary work, rather than a compilation, since "the work itself" contains some degree of creativity. ${ }^{125}$ In addition, the Court

${ }^{119}$ Patry, supra note $44, \S 3: 31$.

${ }^{120}$ Southco, Inc. v. Kanebridge Corp., 390 F.3d 276, 282 (3rd Cir.2004).

${ }^{121}$ Bridy, supra note 57, at 18 .

${ }^{122}$ Urantia Found v. Maaherra, 114 F.3d 955, 957 (9th Cir. 1997).

${ }^{123}$ Id. at 959.

${ }^{124} \mathrm{Id}$.

${ }^{125}$ Urantia Foundation v. Maaherra, 895 F.Supp. 1337, 1338 (D. Ariz 1995) rev'd 114 F.3d 955 (9th Cir. 1997). 
held that copyright does not require that authorship emanate from human effort. ${ }^{126}$ For the Court, it follows that the issue of whether the work is created by celestial beings is irrelevant to consider the work as literary within the meaning of the Act. ${ }^{127}$

Melville and David Nimmer support the District Court's position and does not interpret the work in question as a composite work, but rather a literary work on the basis that the members of the group, by compiling uncopyrightable components into a single work, did not individually engage in creative selection. ${ }^{128} \mathrm{He}$ further cites the English case, Cummins v. Bond, where the issue of celestial authorship was also discussed. ${ }^{129}$ In that case, the plaintiff, who was a medium and had experience in "automatic writing," 130 generated a script called "The Chronicle of Cleophas" during one séance with her client who later adapted it for publication in altered form. ${ }^{131}$ The judge declined to extend copyright to someone who "is already domiciled on the other side of the inevitable river." 132 Given that the plaintiff claimed to communicate and cooperate with a celestial being, and to have later translated the words of said entity into intelligible language, the Court granted copyright to the plaintiff. ${ }^{133}$

In Penguin Books U.S.A., Inc. v. New Christian Church of Full Endeavor, Ltd., the United States Court dealt with the originality of the work called "A Course in Miracles" ("the Course"). ${ }^{134}$ The work was allegedly dictated by Jesus to Dr. Helen Schucman, a medical psychology professor at Columbia University. ${ }^{135}$ Part of the writing was in collaboration with her colleague, Dr. William Thethord. ${ }^{136}$ The defendants copied, printed, and freely distributed resources that consist of significant portions of verbatim quotations from the Course that were

${ }^{126} \mathrm{Id}$.

${ }^{127} \mathrm{Id}$.

${ }^{128}$ Nimmer \& Nimmer, supra note 45, § 2.11, § 9.03 [B].

${ }^{129}$ Id. $\S 2.11$, n. 86.

${ }^{130}$ Automatic writing, also known as psychography, is a method of production of writing that is believed to be dictated by a celestial or psychical entity via the hand of psychic or medium. Psychography OXFORD DICTIONARIES, https://en.oxforddictionaries.com/definition/psychography (last visited Mar. 12, 2018).

${ }^{131}$ Blewett Lee, Copyright of Automatic Writing, 13 VA. L. R. 22, 22 (1927)

(citing Cummins v. Bond [1926. C. 1059.] [1927] 1 Ch. 167 (Eng.)).

${ }^{132}$ Nimmer \& Nimmer, supra note 45, $\S 2.11$ (citing Cummins v. Bond [1926.

C. 1059.] [1927] 1 Ch. 167, 175 (Eng.)).

${ }^{133} \mathrm{Id}$.

${ }^{134}$ Penguin Books U.S.A., Inc. v. New Christian Church of Full Endeavor, Ltd., 2000 U.S. Dist. LEXIS 10394, at *4 (S.D.N.Y. July 21, 2000).

${ }^{135}$ Id. at $* 6$.

${ }^{136} I d$. at $* 7-8$. 
translated into foreign languages without the plaintiff's consent. ${ }^{137}$ The Court accepted Dr. Schucman as an author of the Course as a "compilation of facts" on the ground that: (i) she started the arrangement of materials with assistance from others; (ii) the important aspects of the work were directly reflected directly through Dr. Schucman, assuming that the Course was dictated by Jesus; and (iii) even if the Course did not reflect her personal preferences, the dictated output by Jesus was later edited, for example, personal references were removed, punctuation was added, subheadings of chapters were arranged, and so on. ${ }^{138}$ Also, the Court accepted the Course as a literary work authored by Dr. Schucman on the basis that dictation from a non-human source should not preclude the work being copyrightable. ${ }^{139}$

Bridy is of the opinion that the Courts have constantly held that copyright exists in psychographic works even though the non-human origin of the work is not the factual issue. ${ }^{140}$ She therefore utilizes this analogy to defend the position that AI-generated works are copyrightable within the meaning of the Act. ${ }^{141}$ However, the case law in these types of works is vague and the same analogy cannot be applied to AI-generated works. First, Courts in most psychographic cases have relied on the selection and arrangement criteria. ${ }^{142}$ There is, however, no human intervention like arrangement and selection before or after AI generates copyrightable subject matter. ${ }^{143}$

Secondly, although Courts have accepted works dictated by celestial beings as being a literary work in specific cases, ${ }^{144}$ this does not mean that AI-generated works would be given the same consideration. This is evidently true, since the Court rejected the authorship claims of a macaque, which is biologically one of the most similar creatures to

${ }^{137}$ Id. at $* 22$.

${ }^{138} I d$. at $* 32-34$.

${ }^{139}$ Id. at *34, *36.

${ }^{140}$ Bridy, supra note 57 , at 20 .

141 See id.

${ }^{142}$ See Penguin Books U.S.A., Inc., 2000 U.S. Dist. at *32-34 ("[T]he Course can be protected as a particular compilation of facts, where the originality lies in the arrangement and selection of thee material."); Urantia Found. v. Maaherra, 114 F.3d 955,959 ( $9^{\text {th }}$ Cir. 1997) ("We hold that the human selection and arrangement of the revelations in this case could not have been so 'mechanical or routine as to require no creativity whatsoever."').

${ }^{143}$ See, e.g., Robert Yu, The Machine Author: What Level of Copyright Protection is Appropriate for Fully Independent Computer-Generated Works?, 165 U. PA. L. REV. 1245, 1247 (2017) ("[I]n the case of machine-authored work, there is no distinct human author driving the creative process through composition, arrangement, selection, or direction.").

${ }^{144}$ Urantia Foundation, 895 F.Supp. at *1338; Penguin Books U.S.A., Inc., 2000 U.S. Dist. at *43-45. 
human beings. ${ }^{145}$ The Court reasoned that neither the concept of authorship nor the statutory language of the Act implicitly encompasses animals. ${ }^{146}$ If Bridy's analogy is valid, the Court should have accepted the authorship of Naruto, the name given to the macaque, who is a more concrete and intelligent creature for the purposes of assigning copyright than a celestial being, an entity whose existence nobody, apart from the medium, has witnessed, either spiritually or physically. However, what Bridy failed to consider in applying her analogy, is that the Court simply did not prefer to trespass the territory of faith. ${ }^{147}$

\section{The Evaluation of Case Law and Suggestions for the Future}

In light of the case law, it is obvious that originality is the constitutional essence of copyright. ${ }^{148}$ Despite this, courts, along with Congress, have failed to provide any useful definition of originality. What we can imply from case law is that the courts have always assumed "originality" to be an attribute of works produced only by human beings. ${ }^{149}$ Although it is soft law, ${ }^{150}$ the practices of United States copyright plainly require that the work will be registered only if the work is created by a human, ${ }^{151}$ whereby some human creativity or intervention is detected. ${ }^{152}$

On the other hand, Arthur Miller argues that the reference to the "authors" in the Constitution does not preclude the protection of AIgenerated works because that reference does not require "authors" to be

${ }^{145}$ Naruto v. Slater, 2016 U.S. Dist. LEXIS 11041, *10 (N.D. Cal. 2016). Bridy gives no reason for her exclusion of animals from her analogy. Bridy, supra note 57 , n. 155 .

${ }^{146}$ Naruto, 2016 U.S. Dist. at *8-10.. ("[T]he Copyright Act does not "plainly" extend the concept of authorship statutory standings to animals. Naruto is not an "author" within the meaning of the Copyright Act.").

${ }^{147}$ Urantia, 895 F.Supp. at 1338. (stating, "If I were to declare The Urantia Book to be a divine revelation dictated by divine beings, I would be trampling upon someone's religious faith. If I declared the opposite, I would be trampling upon someone else's religious faith. I shall do neither.").

${ }^{148}$ L. Ray Patterson \& Craig Joyce, Monopolizing the Law: The Scope of Copyright Protection for Law Reports and Statutory Compilations, 36 UCLA L. REV. 719, 763 (1989).

${ }^{149}$ Community for Creative Non-Violence v. Reid, 490 U.S. 730, 737 (1989) ("As a general rule, the author is ... the person who translates an idea into a fixed, tangible expression entitled to copyright protection.") (emphasis added).

${ }^{150}$ Inhale, Inc. v. Starbuzz Tobacco, Inc., 755 F.3d 1038, 1041 (2014) ("When interpreting the Copyright Act, we defer to the Copyright Office's interpretations in the appropriate circumstances.").

${ }^{151}$ The United States Copyright OfFice, Compendium of U.S. Copyright OfFice Practices Section 306 (3rd ed. 2017).

${ }^{152} I d$. Section 312.3. 
human. Instead, the text only requires that humans be the cause of the birth of the work. ${ }^{153}$ Moreover, the reason why neither "works of authorship" nor "works" was defined in the Act is because room for flexibility was intentionally left for the courts. ${ }^{154}$ The constitutional ground for copyright protection has a close relationship with economic incentives. ${ }^{155}$ The legislative history of copyright demonstrates that bringing the particular classes of writings within the realm of copyright is reliant not only on the nature of the writings, but also their commercial significance to the national economy. ${ }^{156}$ It is estimated that by 2020 , the AI industry will be worth $\$ 70$ billion, up from $\$ 8.2$ billion in 2013. ${ }^{157}$ As discussed earlier, the revolution in AI has already greatly influenced the entertainment industry, ${ }^{158}$ and is likely to have further impact on the creative industries. ${ }^{159}$ It is expected that many infringement cases will occur once AI-generated content becomes widespread. ${ }^{160}$ The courts, therefore, should pursue an objective approach when assessing the originality of the works based on an average observer's perspective and its resemblance to existing works, ${ }^{161}$

${ }^{153}$ Arthur R. Miller, Copyright Protection for Computer Programs, Databases, and Computer-Generated Works: Is Anything New Since CONTU, 106 HARV. L. REV. 977, 1065 (1993).

${ }^{154}$ Garcia v. Google, Inc., 786 F.3d 733, 741 (9th Cir. 2015).

${ }^{155}$ Goldstein v. Cali., 412 U.S. 546, 564 (1973) (arguing that since the technology allowed to precisely record the performance and duplicate it, piracy of performances arose in practice in California which then adversely affected the recording industry in there).

${ }^{156} I d$. at 562 (giving examples of the writings that had earlier been not copyrightable subject matter, e.g., musical compositions, photographs and photographic negatives, paintings, drawings, chromos, statuettes, statuary, models or designs of fine art, motion pictures and sound recordings).

${ }^{157}$ Tech CEOs Declare This the Era of Artificial Intelligence, FORTUNE (June 3, 2016), http://fortune.com/2016/06/03/tech-ceos-artificial-intelligence/.

${ }^{158}$ See, e.g., Josh Constine, Need Music for A Video? Jukedeck's AI Composer Makes Cheap, Custom Soundtracks, TeCHCRUNCH (Dec. 7, 2015), https://techcrunch.com/2015/12/07/jukedeck/.

${ }^{159}$ Andres Guadamuz, Do Androids Dream of Electric Copyright? Comparative Analysis of Originality in Artificial Intelligence Generated Works, 2 INTELL. PROP. Q. 169, 185 (2017).

${ }^{160}$ Gregor Pryor, Viewpoint: Why Artificial Intelligence Will Change the Game for the Music Biz, MusicWEEK (Mar. 20, 2017), http://www.musicweek.com/opinion/read/viewpoint-why-artificial-intelligence-willchange-the-game-for-the-music-biz/067890. See also, Plotkin, supra note 60 , at 10 (asserting that companies have already started to patent their AI-software and inventions produced by it and the history of patent law in technological fields demonstrates that many conflicts are about to arise on ownership of AI-generated inventions in the courts).

${ }^{161}$ Shlomit Yanisky-Ravid \& Luis Antonio Velez-Hernandez, Copyrightability of Artworks Produced by Creative Robots and Originality: The Formality-Objective 
rather than subjective factors. ${ }^{162}$ This would enable judges to better assess the originality of AI-generated works, as intent and consciousness of AI systems is still not clearly defined and understood. ${ }^{163}$

Another reason for accepting AI-generated works as copyrightable subject matter is that copyright law has traditionally kept pace with technological advancements. ${ }^{164}$ Works that had earlier not been copyrightable, for example, musical compositions, photographs and photographic negatives, sound recordings, were later included either through the Act or the broadening of the legal doctrines of the Court. ${ }^{165}$ For example, in Goldstein v. California, upon the contention of the defendant that recording of musical performances was previously excluded from copyright protection by the Congress in the Act of 1909, the Court explicitly stated that there was a great technological difference between that time and 1973 when the case was decided. ${ }^{166}$ In BurrowGiles, one side argued that a photograph should not be considered as a writing nor the creation of an author for the purposes of copyright on the ground that it is merely reproduction of the precise features of a natural entity or human being. ${ }^{167}$ The Court reasoned that the absence of implicit reference to photographs in the Act of 1802 is the result of the fact that the mechanism of photography only became known and disseminated much later. ${ }^{168}$

Although artificial intelligence will likely lead to a significant departure from current notions of copyright law, federal courts and legislative bodies should take action to address technological change to

Model, 19 MinN. J. L. SCI. \& TECH. 1, 40 (2018) (reasoning that "the subjective analysis might be troublesome because it is an immeasurable criterion. The artist's intentions, ... are mostly . . hidden and unknown. Therefore, to avoid confusion and speculation ... courts should adopt the objective approach.").

162 J.H. Reichman, Goldstein on Copyright Law: A Realist's Approach to a Technological Age, 43 STAN. L. R. 943, 954 (1991) (referring to cases in which qualitative standards, purposefully or not, were employed when assessing originality of the works). See also PETER DECHERNEY, HOLly WOOD's COPYRIGHT WARS: From EDISON TO THE INTERNET 107 (2012) (noting that aesthetic evaluation continues to be an inevitable component of the judgments in the courts when they compare art).

${ }^{163}$ Y anisky-Ravid \& Velez-Hernandez, supra note 161, at 35.

${ }^{164}$ Madeleine de Cock Buning, Autonomous Intelligent Systems as Creative Agents Under the EU Framework for Intellectual Property, 7 EUR. J. RISK RUG. 310, 319 (2016) (arguing that the widespread of photographs, software, and databases resulted in new types of copyright to keep pace with technological innovations).

165 Goldstein, 412 U.S. at 562.

${ }^{166} \mathrm{Id}$. at 564.

${ }^{167}$ Burrow-Giles, 111 U.S. at 56.

${ }^{168} \mathrm{Id}$. at 58 . 
ensure they preserve the purpose of the constitutional clause which is to progress useful arts. ${ }^{169}$ In this context, the questions of which physical or artificial entity should be rewarded, and for what duration copyright protection should extend, are the most pivotal questions that need to be answered.

\section{JUSTIFYING AI-GENERATED WORKS: THE UTILITARIAN APPROACH}

Copyright is granted to authors through a clause in the United States Constitution 170 which aims to encourage the dissemination of knowledge. The clause references operative terms, such as "authors," "writings," and "science."171 In Mazer v. Stein, the Court interpreted the "economic philosophy" that underlies the constitutional clause as "the conviction that encouragement of individual effort by personal gain" through incentives is the ideal way to improve the common good by the outputs of artists and inventors per se. ${ }^{172}$ Copyright protection is based on binary principles: (i) authors' creative activities are beneficial for the general public and; (ii) limited monopoly is an essential means to induce those activities, thereby reflecting a public policy that precludes private monopolies in the absence of a pivotal balancing return. ${ }^{173}$ United States copyright, therefore, is heavily based on utilitarian theory. ${ }^{174}$

The utilitarian-theory approach simply argues that the creation of a work as a public good requires expending skill, labor, and money, whereas the copying of such work by its creator, or entities to whom such work has been made available, has relatively low cost. ${ }^{175}$ If the price of the copies or the price of the work itself is reduced to marginal

${ }^{169}$ See, e.g., Ben Hattenbach \& Joshua Glucoft, Patents in An Era of Infinite Monkeys and Artificial Intelligence, 19 STAN. TECH. L. REV. 32, 51 (2015)

(regarding patenting computer-generated inventions, an intellectual property protection would serve to the purpose of the Constitution).

${ }^{170}$ See U.S. ConsT. art. I, § 8, cl. 8.

${ }^{171}$ Constant v. Advanced Micro-Devices, Inc., 848 F.2d 1560, 1564 n.4 (Fed. Cir. 1988) (arguing that the term "Science" implies copyright because it was interpreted more broadly in the eighteenth century, whereas "useful Arts" is employed to cover patents).

${ }^{172}$ Mazer v. Stein, 347 U.S. 201, 219 (1954) (emphasis added).

173 Twentieth Century Music Corp. v. Aiken, 422 U.S. 151, 156 (1975), superseded by statute, Copyright Act of 1976, Pub. L. No. 94-553, 90 Stat 2541, as reprinted in Nimmer \& Nimmer, supra note 45, § 1.03[A][1] n.7.

${ }^{174}$ See William Fisher, Theories of Intellectual Property, in NEW ESSAYS IN THE Legal and Political Theory of Prop. 168, 174 (Stephen Munzer ed., 2001).

${ }^{175}$ William M. Landes \& Richard A. Posner, An Economic Analysis of Copyright Law, 18 J. LeGAL STUD. 325, 326 (1989). 
cost by the creator, ${ }^{176}$ this may discourage copiers from disseminating copies; yet, the creator's income would be insufficient to cover the cost associated with the skills, labor, and other resources expended to make the work. ${ }^{177}$ By granting copyright protection to the copyright owner which can preclude others from cloning his work, a balance between the costs of restricting access to a work and the advantages of providing incentives to generate the work is achieved. ${ }^{178}$ Once anyone is allowed to freely duplicate and commercialize a work, the market price of the work will rapidly fall to the marginal cost of copying it. ${ }^{179}$ It follows that under such conditions, creators are disincentivized to produce original creative work in the first place, due to limited chance of achieving an adequate return. ${ }^{180}$

The fact that AI models require no economic incentive thus refutes the traditional approach, which is grounded on the need to promote the fruits of human effort. ${ }^{181}$ Robert $\mathrm{Yu}$ opines that computer software cannot be incentivized legitimately or financially because it only obeys given instructions. ${ }^{182}$ Moreover, he contends that extending incentive justification to programmers is not convincing since they already hold a copyright on the software. ${ }^{183}$

It is true that AI-systems do not need incentives to create copyrightable works. ${ }^{184}$ That said, the effort of programmers in designing these systems should not be undercut. ${ }^{185}$ As argued above, computers still lack autonomy and we cannot expect, at least for now, that they will disseminate works themselves, enter a contractual relationship with licensees, sue against infringement, or exhibit paintings at a museum without direct human control and intervention. ${ }^{186}$ Creating AI-systems that achieve great creativity, be it exploratory or transformational, requires extensive technical knowledge in more than

${ }^{176}$ Marginal Cost, A DiCTIONARY OF ECONOMICS (5th ed. 2017).

${ }^{177}$ Landes \& Posner, supra note 175, at 326.

${ }^{178}$ Richard A. Posner, Intellectual Property: The Law and Economics Approach, 19 J. ECON. PERSP. 57, 57 (2005).

${ }^{179} \mathrm{Id}$. at 58-59 (arguing that when "the creator has no right to exclude others from access to the property, the price is forced down to marginal cost by competition from copiers").

${ }^{180}$ Landes \& Posner, supra note 175 , at 328.

${ }^{181}$ See, e.g., Mazer v. Stein, 347 U.S. 201, 219 (1954) (interpreting the constitutional clause as "encouragement of individual effort by personal gain.").

${ }^{182}$ See Yu, supra note 143, at 1249.

${ }^{183} \mathrm{Yu}$, supra note 143, at 1249.

${ }^{184} \mathrm{Yu}$, supra note 143 , at 1249.

${ }^{185}$ Miller, supra note 153, at 1067 ("A computer will not refuse to function if its output does not receive copyright protection, but the people who are motivated to prepare its programming and operate the system might.").

${ }^{186}$ Miller, supra note 153 , at 1066. 
one domain. ${ }^{187}$ Moreover, programmers are initially driven to design AIsystems that are capable of generating highly creative output ${ }^{188}$ so that the ties between these systems' output and the programmers' intention should not be neglected.

However, one possible objection could come from the argument that the cost of creating copyrightable works by AI-systems will fall so far that the calculation of optimal copyright protection in utilitarian theory will collapse in so far as the cost of creation of a work is taken into account. ${ }^{189} \mathrm{Yu}$ therefore argues that the adaptation of such work into existing copyright protection would not bring advantageous results because individuals may hold copyrights on an indefinite number of works, thus stifling creative efforts in the future (through the creative adaptation of existing works). ${ }^{190}$ Computers have already been effectively and widely employed in creative industries and machine and human collaboration has resulted in more creative works being published. ${ }^{191}$ Conversely, AI-systems should not be seen as replacing human authors, since obviously they can evolve together.

The upshot is that if AI-generated works are not legitimately accepted as a copyrightable work, the programmer may simply elect not to disclose the work to the public or claim authorship of the work herself (over the AI-system), thereby failing to give full credit to the AI-system for its contribution. ${ }^{192}$ If the programmer's effort is given insufficient reward in the first instance, she will have little incentive to contribute to the design and development of AI-systems in general, since any subsequent output will be freely copied by others. ${ }^{193}$ Schlomit YaniskyRavid rightly points out that although programmers' roles are only "ancillary" to the creative process itself, they should nonetheless be

${ }^{187}$ See supra Section 2.2.2.

${ }^{188} \mathrm{Yu}$, supra note 143, at 1256-57.

${ }^{189}$ See infra Section 4.1.

${ }^{190} \mathrm{Yu}$, supra note 143, at 1250.

${ }^{191}$ See, e.g., Jani McCutcheon, The Vanishing Author in Computer-Generated Works: A Critical Analysis of Recent Australian Case Law, 36 MeLB. U. L. REV. 915, 966 (2013) ("If substantial computer generation prevents authorship, that fact alone will vitiate copyright in many, and perhaps most, computer-created productions.").

${ }^{192}$ Ryan Abbott, Artificial Intelligence, Big Data and Intellectual Property: Protecting Computer-Generated Works in the United Kingdom, in RESEARCH HandBook on Intellectual Prop. AND Digital Technologies 11 (Tanya Aplin ed., 2017) (noting that at present, individuals are declaring themselves as inventors of AI-generated inventions although they did not intervene during the inventive process).

${ }^{193}$ Shlomit Yanisky-Ravid, Generating Rembrandt: Artificial Intelligence, Copyright, and Accountability in the 3A Era-The Human-like Authors Are Already Here-A New Model, 2017 MiCH. ST. L. REV. 659, 702 (2017). 
encouraged to contribute to improving $\mathrm{AI}$-system programming and overseeing the functioning of AI systems. ${ }^{194}$

Since many types of creative work do not need require monetary incentive to be authored and distributed and are instead being driven by other, arguably more noble, motivations, Lydia Loren has proposed "thin" protection for such works. ${ }^{195}$ She argues that a utilitarian approach, which grants limited monopolies against the risk of underproduction, still applies in such cases, given that copyright protection can be granted as a matter of degree. In other words, there is no barrier to awarding less protection where there is little or no risk of underproduction. ${ }^{196}$ Hence, in order to ensure a balance between the need to motivate programmers and the public benefit, it could be argued that AI-generated works should receive less copyright protection, since these outputs are far less costly to produce than human-authored works. ${ }^{197}$ For example, the United Kingdom's Copyrights, Designs and Patents Act ("CDPA") recognizes that the person undertakes the necessary arrangements for the creation of the literary, dramatic, musical or artistic work as the author in case of computer-generated works. ${ }^{198}$ However, the duration of copyright for computer-generated works is fifty years, starting from the year after the work was made. ${ }^{199}$ This approach differs from the general rule which grants copyright protection for fifty years after the author's death. ${ }^{200}$

\section{CANDIDATES FOR AUTHORSHIP}

\section{A. The AI-System}

The first option for awarding authorship is to the AI-system itself. However, to do so requires that we first answer the question of whether such a system could be accorded legal personality. James Boyle notes that the extension of legal personality in United States history has occurred progressively, through a process of public reasoning and moral suasion; for example, women and African-Americans, once excluded,

${ }^{194}$ See id. at 701-05.

${ }^{195}$ Lydia Pallas Loren, The Pope's Copyright-Aligning Incentives with Reality by Using Creative Motivation to Shape Copyright Protection, 69 LA. L. REV. 1, 3 (2008).

${ }^{196} \mathrm{Id}$.

${ }^{197}$ Anastasiya Kiseleva, Comment, What is Artificial Intelligence and Why Does It Matter for Copyright?, 4IP COUNCIL (Jan. 2019).

${ }^{198}$ Copyrights, Designs and Patents Act (CDPA) 1988, c. 48, § 9(3) (Eng.).

${ }^{199}$ Id. $\S 12(3)$.

${ }^{200}$ Id. $\$ 12(1)$. 
were later rightfully recognized as legal persons. ${ }^{201}$ Therefore, the reasoning goes, in the not-too-distant future such status will be extended to AI-systems as new evidence is brought to the public debate. ${ }^{202}$ Indeed, Lawrence Solum's proposal to consider granting legal personality to AI-systems relies on evidence from cognitive science that affirms AI-systems processing is similar to that generated in human minds. ${ }^{203}$

The recognition of legal personality by courts or legislative authorities generally responds to legal, political or moral pressure. ${ }^{204}$ In other words, it is never a simple reflection of general principles, but rather responds to a "vortex of discursive imperatives." 205 Accepting artificial agents as legal persons is inter alia, a decision requiring pragmatic considerations, such as the social impacts, rather than simple conceptual reasoning. ${ }^{206}$ It would seem a little early to grant sole authorship or ownership of works to AI-systems since there is no evidence that they possess attributes typically seen as intrinsically human such as emotion, consciousness, intentionality, or free will..$^{207}$ Even if AI-systems were recognized as legal persons, the need for copyright protection for them should be discussed since they will not need any incentive to create. ${ }^{208}$

Karl Milde reckons that the computer could be considered at least co-author with the programmer or the person who fed the data, or under specific circumstances a sole author or discoverer of the work if it

${ }^{201}$ James Boyle, Endowed by Their Creator? The Future of Constitutional Personhood, in The Future of Constitution (Mar. 9, 2011).

${ }^{202} \mathrm{Id}$.

203 Lawrence B. Solum, Comment, Legal Personhood for Artificial Intelligences, 70 NC. L. REV. 1231, 1259 (1992) (warning that a definite answer to the question of whether artificial intelligences should be entitled to a type of legal personhood cannot be answered before the question becomes an urgent, and further considering that future interactions between $\mathrm{AI}$ and humans could change our perspective).

${ }^{204}$ Samir Chopra \& Laurence F. White, A LEGAL ThEORY of Autonomous ARTIFICIAL AGENTS 155 (2011).

${ }^{205} \mathrm{Id}$.

${ }^{206}$ Id.; see also, Jeremy A. Cubert \& Richard G.A. Bone, The Law of Intellectual Property Created by Artificial Intelligence, in RESEARCH HANDBOOK ON THE LAW OF ARTIFICLAL INTELLiGENCE 411, 425 (Woodrow Barfield \& Ugo Pagallo eds., 2018) ("Should Smart AI be entitled to intellectual property rights and will there be a net benefit to the public from such an arrangement? The answer to this question may ultimately be tied to the future status of Smart AI...in our society.").

${ }^{207}$ See supra Section 1.

${ }^{208}$ Daniel Schönberger, Deep Copyright: Up - And Downstream Questions Related to Artificial Intelligence (AI) and Machine Learning (ML), in DROIT D'AUTEUR 4.0 / COPYRIGHT 4.0 145, 155 (Jacques De Werra ed., 2018). 
differs from the input. ${ }^{209}$ However, the Court's assumed position on non-human authorship became self-evident in the so-called "monkeyselfie" case. ${ }^{210}$ The dispute arose from a photograph taken by the macaque Naruto, in Indonesia using a free-standing tripod set up by British photographer David Slater for the express purpose of making it as simple as possible for the monkeys to take photographs. ${ }^{211}$ People for the Ethical Treatment of Animals ("PETA") brought a law suit on behalf of Naruto against Mr. Slater on the ground that the copyright on the photograph belongs to him since he made the intentional and deliberate arrangements without any assistance from Mr. Slater. ${ }^{212}$ The District Court found that although Naruto engaged in "independent, autonomous action" to author the photograph, the Act does not implicitly extend authorship to animals. ${ }^{213}$ To extend non-human authorship, the Court stated, is an issue that should be reported to Congress and the President. ${ }^{214}$ By the same token, recognizing AIsystems as an author of the work does not seem to be possible in the near future unless the legislative bodies plainly mention in the Act that non-human entities are eligible for authorship. ${ }^{215}$

Many commentators have pointed to the "work-for-hire" model as one that could be applied to AI-generated works. ${ }^{216}$ Work prepared for an employer or other entity by an employee or agent is commonly copyrighted not by the worker herself but by the organization or entity that has commissioned the work to be produced..$^{217}$ It is true that the Act stipulates an exception for authorship in such cases. ${ }^{218}$ The Act defines a "work made for hire" in two distinct ways: (i) a work created by an employee "within the scope of his or her employment;" and (ii) specially ordered or commissioned works, which fall within the

${ }^{209}$ Karl F. Jr. Milde, Can a Computer Be and Author or an Inventor, 51 J. PAT. OFF. SOC'Y 378, 403 (1969).

${ }^{210}$ Andres Guadamuz, Can the Monkey Selfie Case Teach Us Anything About the Copyright Law?, WIPO MAGAZINE, Feb. 2018, at 40, 40-47.

${ }^{211} \mathrm{Id}$. at 40.

${ }^{212} \mathrm{Id}$.

${ }^{213}$ Naruto, 2016 WL 362231, at*3.

${ }^{214} \mathrm{Id}$. at $* 4$.

${ }^{215}$ See, e.g., Guadamuz, supra note 159 , at 173 . (" $[\mathrm{I}] \mathrm{t}$ is highly unlikely that we will witness any deviation away from personhood as a requirement for ownership, and we are not to witness any sort of allocation of rights towards machines and animals.").

${ }^{216}$ Annemarie Bridy, The Evolution of Authorship: Work Made by Code, 39 COLUM. J. L. \& ARTS 395, 401 (2016); Kalin Hristov, Artificial Intelligence and the Copyright Dilemma, 57 IDEA 431, 446 (2017); Yanisky-Ravid, supra note 194, at 707-16.

${ }^{217} 17$ U.S.C. $\$ 201(b)(2012)$.

${ }^{218} \mathrm{Id}$ 
exhaustive list. ${ }^{219}$ The Supreme Court interpreted the meaning of "employee" within the borders of common law-agency doctrine, and defined him or her as a "hired party in a conventional employment relationship" ${ }^{220}$ The "work made for hire" model is actually a policy consideration, which prioritizes employers' investment over employees' engagement with creative process. ${ }^{221}$

Considering the plain language of the Act and the Court's position, a work-for-hire model for AI-generated works would raise many questions regarding its implementation into agency law. First, under that model, only legal persons can freely enter into the contractual restraints associated with an agreement with an employer and, as discussed above, an AI-system has no legal personhood. ${ }^{222}$ Second, there is no indication that the Congress will pursue the same policy considerations for AI-generated works.

\section{B. The Programmer}

It is obvious that the major contribution for creating an AI-system that generates highly creative output comes from the programmer. ${ }^{223}$ The idea behind this approach is that if the programmer had not designed, trained and created AI software, the work would have not been introduced to the world. ${ }^{224}$ As argued above, creating a sophisticated, independent, and creative AI-systems requires a mentally challenging process and a significant investment, which should be rewarded. Darin Glasser contends that since the "sweat of the brow" approach was rejected in Feist, rewarding the programmer for her effort will face the same scrutiny. ${ }^{225}$ In Feist, the dispute in question was the

21917 U.S.C. $\$ 101$ (2012).

${ }^{220}$ Community for Creative Non-Violence v. Reid, 490 U.S. 730, 739-743 (1989) (emphasis added).

${ }^{221}$ Jane C. Ginsburg, The Concept of Authorship in Comparative Copyright Law, 52 DEPAUL. L. REV. 1063, 1088-89 (2003).

${ }^{222}$ See, e.g., RESTATEMENT (THIRD) OF AGENCY $§ 1.04 \mathrm{cmt}$. (AM. LAW InST. 2006) ("[A] computer program is not capable of acting as a principal or an agent as defined by the common law. At present, computer programs are instrumentalities of the persons who use them."); Contra UGA PAGallo, The LAws of RoBOTS:

CRIMES, CONTRACTS, AND TORTS 82 (2013) (arguing that the level of autonomy for robots, which are capable of accomplishing contractual negotiations, executions, or bids, would be sufficient to establish new types of artificial agency).

${ }^{223}$ See Robert C. Denicola, Ex Machina: Copyright Protection for ComputerGenerated Works, 69 RUTGERs U. L. REV. 251, 276-78 (2016); Contra YaniskyRavid, supra note 193, at 684-98.

${ }^{224}$ Yanisky-Ravid, supra note 193, at 689-90.

${ }^{225}$ Darin Glasser, Copyrights in Computer-Generated Works: Whom, If Anyone, Do We Reward?, 2001 DukE L. \& TECH. REV. 0017, 213 (2001). 
copyrightability of raw facts, which could not satisfy the lower threshold of creativity and originality, which is why the Court rejected other approaches as justification of protecting such uncopyrightable facts. ${ }^{226}$ Yet, the examples of AI-generated works discussed above are already eligible for copyright protection.

On the other hand, Pamela Samuelson argues that the programmer should not be entitled to authorship of all AI-generated works in all cases since she might prevent others from obtaining the output by not distributing the AI-software. ${ }^{227}$ While it is clear that the programmer would prefer to capture all the benefits of the AI-software herself, once she elects to exploit the AI-system by distributing the software to third parties, the programmer should no longer claim any right over the output. $^{228}$ Samuelson further contends that granting exclusive authorship of all works to the programmer would be highly problematic in terms of enforceability, as the user would be incentivized not to report any output from the system to the programmer; and it is difficult to determine whether a specific work was generated by the program at all. ${ }^{229}$ Since the programmer will not be the person who causes the work to be fixed in a tangible medium of expression, granting authorship to the programmer in all cases would be a significant departure from the standpoint of legal doctrine. ${ }^{230}$

Samuelson's analysis brings to the forefront the contractual aspects of copyright between interested parties. The programmer has the privilege to set boundaries for the outputs generated by AI-software, like sharing royalties or setting inflated prices for users to access the software, and this ultimately is the subject of contract law. Today, the software industry similarly hinges on such restraints. ${ }^{231}$

The programmer's role in the creative process is analogous to the photographer's decisions discussed in Burrow-Giles, where the arrangement of location, lighting and the pose of the subjects was

${ }^{226}$ Feist, 499 U.S. at 340.

${ }^{227}$ Pamela Samuelson, Allocating Ownership Rights in Computer-Generated Works, 47 U. PITT. L. REV. 1185, 1207 (1986).

${ }^{228} \mathrm{Id}$. at 1208 (otherwise contending the programmer would be over-rewarded by owning all output that a given AI-system generates).

${ }^{229} \mathrm{Id}$.

${ }^{230} \mathrm{Id}$. at $1208-09$.

${ }^{231}$ See, e.g., Julia Dickenson et al., Creative Machines: Ownership of Copyright in Content Created by Artificial Intelligence Applications, 39 EUR. INTELL. Prop. REV. 457, 460 (2017) (the authors who work at Baker \& Mckenzie's London office note that the clients who utilize and develop AI are well advised to incorporate provisions related to ownership of AI-generated works). 
deemed. ${ }^{232}$ In Burrow-Giles, the court recognized the photographer as an author on the ground that she was the one closest to the photographic production process, because she determined the arrangement and truly designed the picture by deciding the position of the subjects and the location in which the subjects were shot. ${ }^{233}$ The Court declared the author of the photograph to be the one who actually represents, generates, or embodies the idea, fancy, or imagination associated with it. $^{234}$ The programmer could therefore be considered to be in an analogous position to the photographer in setting the frame for the subsequent output, even though AI-systems generate more variegated output than a camera does, generally speaking. ${ }^{235}$ To summarize the theoretical and practical perspective, the programmer who invested skill, labor, and other resources to design the AI-system producing the creative output is the best candidate for authorship as far as copyright law is concerned. ${ }^{236}$

${ }^{232}$ Dan Rosen, A Common Law for the Ages of Intellectual Property, $38 \mathrm{U}$. MIAMI L. REV. 769, 804 (1984).

${ }^{233}$ Burrow-Giles, 111 U.S. at 61.

${ }^{234} I d$.

${ }^{235}$ Rosen, supra note 232, at 803-04; see also, Evan H. Farr, Copyrightability of Computer-Created Works, 15 RuTGERs COMPUTER \& TECH. L. J. 63, 73 (1989).

${ }^{236}$ See, e.g., Dickenson et al., supra note 231, at 460 (noting that Japan's intellectual property authorities are now preparing a legal mechanism that protects AI-generated works against use without consent, and guarantees a fair remuneration of the programmers of AI systems); James Wagner, Rise of the Artificial Intelligence Author, 75 Advocate (VANCOUVER) 527, 532 (2017) (proposing that legislating the author be "the party that organizes the creation of the work initially" (i.e., the programmer), would be a practical solution.); Cubert \& Bone, supra note 206, at 425 ("Aiva Technologies has invested time, money, and creativity to develop and improve music creation algorithms....Aiva would like to sell or license the music content developed by the algorithms. The public interest may therefore be served by extending the definition of author to AI under these circumstances -e.g., AI developed and controlled by humans-...otherwise AI-generated music would fall into the public domain, and the incentive to develop the AI in the first place would be greatly reduced."); Raquel Acosta, Artificial Intelligence and Authorship Rights, JOLTDIGEST (Feb. 17, 2012), https://jolt.law.harvard.edu/digest/artificialintelligence-and-authorship-rights. ("If allowing AI developers to claim copyrights in their machine's output incentivizes more creative production, legislators should codify this copyright grant in the law."). 


\section{The Trainer}

Artificial neural networks are essential to the design of creative machines. ${ }^{237}$ After these networks are initially fed with a myriad of data in a respective domain they are trained to analyze the input of data in order to develop a different output. ${ }^{238}$ The training process is so crucial that if the respective data is wrongly selected, it will lead to a gross deviation and ultimately a failure in the process. ${ }^{239}$ For example, this process can be found in the start-up Jukedeck's algorithm, which utilizes trained neural networks to generate music by developing audio and employing an automated production program. ${ }^{240}$ Machine learning fundamentally hinges on both the amount and the quality of data input by the trainer. ${ }^{241}$ Therefore, the trainer has a strong competing claim to authorship of the output.

Although in most cases the trainer and the programmer are the same entity, ${ }^{242}$ in some circumstances, the trainer could be an employee at a technology company or trainers who are not employees of a common employer. Regarding an employment relationship, the first thing to examine is the provisions in the employment agreement related to a "work made for hire" clause. If such a clause is detected, then the employer who hires the trainer is automatically recognized as the author. ${ }^{243}$ In the absence of such an agreement between the parties, the trainer and the programmer should be considered co-authors by applying the conventional rules of copyright as they pertain to joint

${ }^{237}$ See Stephen L. Thaler, Neural Networks That Autonomously Create and Discover, IMAGINATION ENGINE, http://imagination-engines.com/iei_pcai.php (last visited July 20, 2019).

${ }^{238}$ See Peter M. Todd, A Connectionist Approach to Algorithmic

Composition, 13 COMPUTER MUSIC J. 27, 27-31 (1989) (arguing that novel melodies would be generated by training specific melodies and employing the network's existing generalization ability).

${ }^{239}$ Bo Han et al., Co-teaching: Robust Training of Deep Neural Networks with Extremely Noisy Labels, CENTRE FOR ARTIFICIAL INTELLIGENCE, UNIV. OF TECH. SYDNEY, Oct. 30, 2018 , at 4.

${ }^{240}$ Alex Marshall, From Jingles to Pop Hits, A.I. Is Music to Some Ears, N.Y. TiMes (Jan. 22, 2017), https://www.nytimes.com/2017/01/22/arts/music/jukedeckartificial-intelligence-songwriting.html.

${ }^{241}$ Thomas Burri, International Law and Artificial Intelligence, 60 GERMAN YEARBOOK OF INT'L LAW, 91, 93 (2017) (describing the general connection between artificial intelligence and legal work).

${ }^{242}$ See generally Acosta, supra note 236 (describing that a programmer who trains and creates a machine receives copyright protection in the underlying software).

24317 U.S.C. $\$ 201(b)$. 
authorship. ${ }^{244}$

\section{The User}

One of the first government reports on artificial intelligence, the Final Report on the National Commission on New Technological Uses of Copyrighted Works ("CONTU"), found AI-systems to be quite immature and treated computers as analogous to technologies like cameras and typewriters. Namely, CONTU considered AI as tools that produce outputs only under instruction from human users. It followed that the user was recognized as the author of such output. ${ }^{245}$ In 1986, Congress published the Office of Technology Assessment Report ("OTA"), which criticized CONTU's treatment of computers as merely inert tools and stressed the increasing sophistication of computers technology. ${ }^{246}$ The capacity for computers to be co-creators of works, the report found, made it increasingly difficult to distinguish the rights of users and programmers, at least as far as authorship is concerned..$^{247}$

Samuelson reckons that since the user of a computer-generated work arranges, selects, edits, polishes, or substantially modifies the raw output into a fixed product that is commercially valuable, and thereby directly causes the birth of that work, she should be recognized as its author for copyright purposes. ${ }^{248}$ In addition, Samuelson points out that there could be situations in which the user has more technical knowledge to exploit the raw output than the programmer. ${ }^{249}$ However, this proposal is vulnerable to critique since merely employing an AIsystem does not require any creativity or skills for the creation of the

244 See Final ReP. OF THE NAT'L COMM'N ON NEW TECH. USES OF COPYRIGHTED WORKS at 45 (1979) [hereinafter CONTU Final Report] ("[C]omputers... may be used to produce writings that lack the degree of originality held necessary to copyright...Finally we confront the question of who is the author of a work produced through the use of a computer... When the authors work together as a voluntary team and not as employees of a common employer, the copyright law with respect to works of joint authorship is as applicable here as to works created in more conventional ways...").

${ }^{245} I d$. at $44-45$.

${ }^{246}$ Office of Tech. Assessment, Intellectual Prop. Rights in an Age of Elecs. and Info. (Apr. 1986).

${ }^{247}$ U.S. Cong., Office of Technology Assessment, Intellectual Property Rights in an Age of Electronics and Information 152 (1986).

${ }^{248}$ Samuelson, supra note 227, at 1202 (It should be noted that when Samuelson wrote her article in 1986, cutting-edge AI techniques were not yet developed and the user's intervention, selection or arrangement was still necessary to create a computer-generated work).

${ }^{249} I d$. 
work. ${ }^{250}$ The more sophisticated AI-systems become, the less the user intervenes through selection, arrangement, or editing, making it increasingly difficult to defend the idea of user authorship. ${ }^{251}$

On the other hand, if the program is distributed to the public, the opportunity for gaining authorship could be provided for the end users to own the raw output. ${ }^{252}$ In the end, the main purpose of purchasing such a program is to benefit from its output. However, this opportunity eventually depends on the agreements that are concluded between the programmer and the end user. ${ }^{253}$ This would not be the first time that the Congress has left the authorship issue to be resolved via private agreement. ${ }^{254}$ For example, copyrightable elements in a typical sound recording setting divides authorship between the performer or artist and the producer who records the performance and thus arranges the location, captures the sound, and edits it. ${ }^{255}$ Either the performer's performance or the record producer's contribution would be so minimal or absent in the sound recording, Congress has asserted that the Act does not resolve the issue of authorship or ownership in such a case, instead leaving these issues to be concluded via private contractual relationship. ${ }^{256}$ The user's ownership claim to AI-generated works, therefore, should be tied to restraints arising from a private relationship with the programmer.

\section{E. Joint Authorship}

Allocating ownership rights between the user, the programmer and the data proprietor as joint authors is widely discussed as an efficient solution. ${ }^{257}$ It has been argued that joint authorship of the work should be recognized-between the programmer, who is responsible for "concretization" of the output, and the user, who produces

${ }^{250}$ Maria E. Reicher, Computer-Generated Music, Authorship, and Work Identity, 91 GRAZER PHILOSOPHISCHE STUdIEN 107, 109 (2015).

${ }^{251}$ George Krasadakis, Artificial Intelligence: The Impact on Employment and the Workforce, MEDIUM (Jan. 17, 2018), https://medium.com/innovationmachine/artificial-intelligence-3c6d80072416.

${ }^{252}$ Gerald Dworkin \& Richard D. Taylor, Blackstone's Guide to the Copyright, Designs and Patents Act 1988: The Law of Copyright and Related Rights 185-86 (1989).

${ }^{253}$ See Michael Terasaki, Do End User License Agreements Bind Normal People?, 41 W. ST. U. L. REV. 467, 468 (2014).

${ }^{254}$ Russ Pearlman, Recognizing Artificial Intelligence (AI) as Authors and Inventors Under U.S. Intellectual Property Law, 24 RICH. J. L. AND TECH. no. 2 , 2018.

${ }^{255}$ H.R. REP. No. 92-487, at 5 (1971).

${ }^{256} \mathrm{Id}$.

${ }^{257}$ See generally Samuelson, supra note 227. 
unforeseeable outputs from the programmer's work by filing, arranging, and editing. ${ }^{258}$

To determine whether there is truly joint authorship in question, the meaning of joint authorship initially should be clarified. The Act stipulates that the authors of a joint work are deemed to be co-owners of the work. ${ }^{259}$ Pursuant to the Act, a joint work is defined as "a work prepared by two or more authors with the intention that their contributions be merged into inseparable or interdependent parts of a unitary whole." 260 Legislative history demonstrates that a work is accepted as "joint" if the authors cooperated, or if each of the authors entered the collaboration "with the knowledge and intention" that her efforts would be combined with the contributions of the other authors to produce "inseparable and interdependent parts of a unitary whole."261 The essential part of a joint work, Congress states, is the author's "intention" that the parts be integrated in a single work at the time the writing is fixed. ${ }^{262}$

Regarding AI-generated works, joint authorship between the programmer and the user is highly doubtful. Assuming, arguendo, that the programmer sold or licensed the AI-system to the user, and the user merely selected, arranged and edited to generate the output, precisely what "effort" has the user contributed? Moreover, it would be problematic to prove the existence the joint intent between the remote user and the programmer to produce a "unitary whole." ${ }^{263}$ However, regarding the trainer and the programmer, if they are in fact different entities, joint authorship could apply because the intention to build a "unitary whole" is implied when they agree to create the AI-system. ${ }^{264}$

Interestingly, "a fictional human author" resolution has been proposed, wherein the Court in litigation presumes the presence of a fictional human author and allocates the appropriate combination of copyrights amongst the owner of the program, the user or the computerowner separately, jointly or partly. ${ }^{265}$ Under this model, the court investigates, via fact-finder, all contracts, facts, customs, and circumstances to decide how much a given party owns copyright in a work. ${ }^{266}$ However, since the fact-finder must determine the quality and

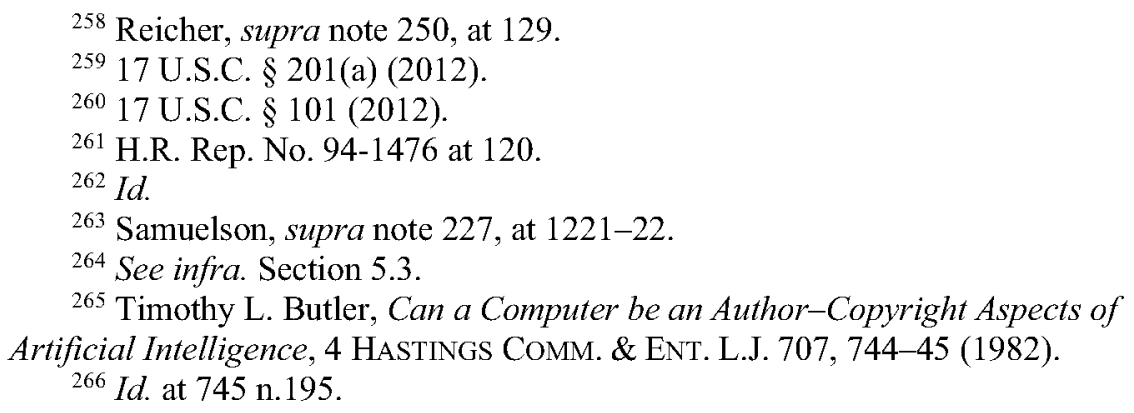


quantity of the contribution of each author in order to assign and apportion the copyrights, this proposal requires litigation for each specific work, and it neglects to specify who would launch the litigation. ${ }^{267}$ This proposal thus provides few practical benefits and brings many legal uncertainties.

\section{F. Public Domain}

It has been argued that since computers do not need be incentivized to generate creative works, any resulting work from an AI-system should be placed immediately in the public domain, since doing so automatically benefits science with essentially no trade-off. ${ }^{268}$ From a law and economics standpoint, another argument is that the most efficient use of resources is to send AI-generated works straight into the public domain, thereby maximizing the benefit for society as a whole. ${ }^{269}$

These proposals wrongly assume that AI-systems are capable of generating creative works ex nihilo. ${ }^{270}$ In other words, while the AIsystem itself requires no incentive, the human agents necessarily linked to it will. ${ }^{271}$ It is true that if machines become fully autonomous, then it is highly likely that copyright protection should be revised in order to address a new generation of works, ${ }^{272}$ yet state-of-the-art AI-systems have not reached that point, as discussed above. Moreover, the legislative bodies and the Courts are already willing to expand IP rewards, particularly for highly technological innovators, to allow both the creative industries and the economy to strengthen. ${ }^{273}$

${ }^{267}$ Evan H. Farr, Copyrightability of Computer-Created Works, 15 RUTGERS COMPUTER \& TECH. L.J. 63, 79 (1989) (citing Butler, supra note 266, at 744-45 \& 745 n.195).

${ }^{268}$ Shamnad Basheer, Artificial Invention: Mind the Machine!, 13 SCRIPTED 334, 357 (2016), https://script-ed.org/wp-content/uploads/2016/12/13-3-basheer.pdf; see also Ralph D. Clifford, Intellectual Property in the Era of the Creative Computer Program: Will the True Creator Please Stand Up?, 71 TuL. L. REV. 1675, 1701-02 (1997) (citing Pamela Samuelson, Allocating Ownership Rights in ComputerGenerated Works, 47 U. PITT. L. REV. 1185, 1199 (1986)); Amir H. Khoury, Intellectual Property Rights for "Hubots": On the Legal Implications of HumanLike Robots As Innovators and Creators, 35 CARDOZO ARTS \& ENT. L.J. 635, 660 (2017); Yu, supra note 143, at 1265.

${ }^{269}$ Mark Perry \& Thomas Margoni, From Music Tracks to Google Maps: Who Owns Computer Generated Works? 26 COMPUTER L. \& SECURITY REV. 621, 625 (2010),

https://papers.ssm.com/sol3/Delivery.cfm/SSRN_ID1753242_code1383303.pdf?abst ractid $=1647584 \&$ mirid $=1$.

${ }^{270}$ See supra notes 101-02 and accompanying text.

${ }^{271}$ See supra notes 101-02 and accompanying text.

272 See generally supra Section 4.1 .

${ }^{273}$ Samuelson, supra note 227, at 1225-26. 


\section{G. The Data Proprietor}

"Big data" of high quality is important for effective machine learning, which is an AI technique employed in creative machines. ${ }^{274}$ A well-trained machine with this kind of data can generate highly creative output. ${ }^{275}$ However, accepting a database owner as an author of AI-generated work would be highly speculative for two reasons. First, the programmer or the user usually needs to obtain permission from the proprietor of the input data, and it is generally difficult to prove that there is any direct link between the data and the output. ${ }^{276}$ The AImodel itself chooses, analyzes, modifies, and applies the data to transform it something different than the input; data in this view is merely analogous to electricity for the AI-system. ${ }^{277}$

Second, although an AI-system fed with a huge database could be more efficient to design a creative machine, there is no sui generis right for database proprietors in the United States as opposed to Europe ${ }^{278}$ due to the effect of Feist decision. ${ }^{279}$ Since the person who compiled such data is not entitled to copyright on the compilation in the United States, ${ }^{280}$ it is therefore very difficult to accept her as an author of an AI-generated work merely because the data so compiled was employed by the AI-system. Moreover, psychological research on copyright reveals that society does not admire too much "newness" in a work. ${ }^{281}$ Therefore, authors are typically attracted to each other such that "artistic communities" produce similar types of works, or they simply keep with fashion, even as they are original and creative. ${ }^{282}$ Assuming that an AI-

${ }^{274}$ See generally Machine Learning What it is and why it matters, SAS, https://www.sas.com/en_us/insights/analytics/machine-learning.html (last visited July 9, 2019).

275 See generally id.

${ }^{276}$ CONTU Final Report, supra note 244, at 45-46.

${ }^{277}$ Colin R. Davies, An Evolutionary Step in Intellectual Property Rights Artificial Intelligence and Intellectual Property, 27 COMPUTER L. \& SECURITY REV. 601,615 (2011).

${ }^{278}$ Directive 96/9/EC, of the European Parliament and of the Council of 11 March 1996 on the Legal Protection of Databases, 1996 O.J. (L 77/20) 25-6 (stating that sui generis rights for databases is recognized as a special property right for databases which encompasses compilations, provided that the investment required to acquire, authenticate and introduce such a database is predominantly made within Europe).

${ }^{279}$ Marshall Leaffer, Database Protection in the United States is Alive and Well: Comments on Davison, 57 CASE WESTERn REs. L. REV. 855, 855-56 (2007).

${ }^{280}$ See Feist, 499 U.S. at 363-64.

${ }^{281}$ Jeanne C. Fromer, A Psychology of Intellectual Property, 104 Nw. U. L. REV. 1441,1445 (2010).

${ }^{282}$ Id. at $1498-99$. 
generated work has some resemblance to the input data - such as genre similarity - the owner of the input data is not automatically made an author of the output. ${ }^{283}$ The role of data is thus nothing more than inspiration in the context of AI-generated works.

\section{STRIKING A BALANCE}

At first glance, the programmer, or in some cases joint authorship between the trainer and the programmer, seems to be the best candidate for authorship in the interests of fostering innovation. The programmer, or co-authors, would likely prefer to distribute the AI-software and would likely agree that the user will own every work that AI-software generates. ${ }^{284}$ In that case, the user needs to be provided an opportunity to improve and own the output, thereby enhancing competition and creativity. ${ }^{285}$ At this point, a historical relationship between a theory of law and technology would enable society to determine the future interaction between the producer of technology and the user. ${ }^{286}$ For example, the manufacturer of a camera or sound-recording machine cannot claim authorship rights on every work these machines generate with the interaction of the user since the producer already grants to the user the right to exploit the product via a purchase agreement. ${ }^{287}$ Although AI-technology is more autonomous than cameras and soundrecording devices, the commercialization of creative AI-systems is analogous. ${ }^{288}$ Society would want to see users benefit from that technology by improving and contributing the output, just as photographers and sound recorders do with purchased technology. This user benefit would see the programmer's sales and return on investment grow. ${ }^{289}$

To encourage users to contribute and improve the output of AIsystems, the proposed solution should give the widest latitude to the Courts to address legal issues related to AI-generated works (i.e., by not

${ }^{283}$ See supra notes $277-278$ and accompanying text.

${ }^{284}$ Robert C. Denicola, Ex Machina: Copyright Protection for Computer Generated Works, 69 RuTGERS U. L. REV. 251, 283-84 (2016).

${ }^{285}$ Christos P. Badavas, MDI Files: Copyright Protection for ComputerGenerated Works, 35 WM. \& MARY L. REV. 1135, 1174 (1994).

${ }^{286}$ Lyria Bennett Moses, Why Have a Theory of Law and Technological Change, 8 MinN. J. L. SCI. \& TECH. 589, 605 (2007).

${ }^{287}$ See Miller, supra note 153, at 1072 ('Is the 'photographer' who does little more than release the shutter any different from the computer operator who simply directs the computer to run an artificial intelligence program? ... If the photograph is a copyrightable work of authorship, there is no apparent reason why the computergenerated work should be treated differently.").

${ }^{288}$ See id.

${ }^{289}$ See Acosta, supra note 236. 
prioritizing programmer claims to authorship). The United Kingdom is a pioneer in this regard as it was the first jurisdiction to recognize computer-generated work as copyrightable subject matter and to allocate authorship to such works. ${ }^{290}$ Pursuant to the CDPA, a computer-generated work is defined as that which is generated in circumstances in which there is no human author. ${ }^{291}$ Furthermore, the CDPA stipulates that the author of a computer-generated literary, dramatic, musical or artistic work shall be the person who "makes necessary arrangements" for the creation of the work. ${ }^{292}$ Many countries have followed the United Kingdom's example and legislated a similar definition in their codes. ${ }^{293}$

The CDPA clause is criticized for being unclear because the person who makes necessary arrangements is not the true author since many parties are present during the creation process. ${ }^{294}$ However, this is also true for human authorship, particularly in collaborative works. ${ }^{295}$ The clause strikes a balance between the programmer and the user due to the sophisticated nature of AI systems where identifying the persons responsible for the creation of the works is highly problematic. ${ }^{296}$ It is true that the user could easily claim that he or she generated the work entirely, thereby failing to give credit to AI. On the other hand, users may still prefer to take credit for AI-generated works to negotiate with clarity, or to escape liability. ${ }^{297}$

In sum, the CDPA is a reasonable pathway that the United States legislature should follow to achieve a balance between the programmer,

${ }^{290}$ See Miller, supra note 153 , at 1052.

${ }^{291}$ The CDPA 1988, c. $10 . \S 178$ (UK).

${ }^{292}$ The CDPA 1988 , c. $1 . \S 9(3)$ (UK).

${ }^{293}$ See, e.g., Copyright Amendment Act 1992, § 1(d) (S. Afr.); Copyright Act 1994, s 5(2)(a) (N.Z.); Copyright Ordinance, (1999) Cap. 528, 8, § 11(3) (H.K.); Copyright and Related Rights Act 2000, $§ 21$ (f) (Act No. 28/2000) (Ir.), http://www.irishstatutebook.ie/eli/2000/act/28/enacted/en/pdf.

${ }^{294}$ Davies, supra note 278, at 601-02.

${ }^{295}$ See, e.g., Graham Dutfield, Collective Invention and Patent Law Individualism, 1877-2012; or, the Curious Persistence of Inventor's Moral Right, in Knowledge Management and Intellectual Property: Concepts, Actors, AND PRACTICES FROM the PASt to the PRESENT 109, 110 (Arapostathis \& Dutfield, eds., 2013) ("Indeed, the individual inventor today has just as prominent a place on patent documents as in the past, albeit accompanied more often as not with the names of one or more colleagues.").

${ }^{296}$ Emily Dorotheou, Reap the Benefits and Avoid the Legal Uncertainty: Who Owns the Creations of Artificial Intelligence, 21 COMPUTER \& TELECOMM. L. REV. 85, 93 (2015); Guadamuz, supra note 159, at 186.

${ }^{297}$ Abbott, supra note 192, at 12. 
the trainer, and the user. ${ }^{298}$ CDPA has been enacted for nearly three decades and has been accurately applied. ${ }^{299}$ Adopting this standard in the United States would also facilitate international harmonization in future. ${ }^{300}$

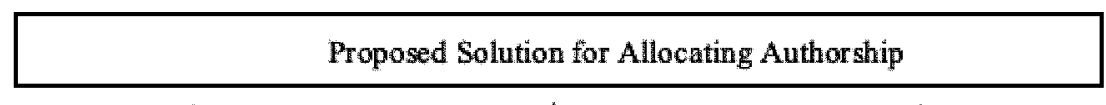

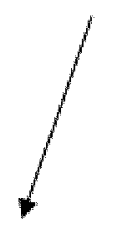

(i)The Programmer

-She contributes the creative process much more than any other actor:

-She is the closest actor in the creative process by designing Al-model.

-She needs to be incentivized to improve and take responsibility for creative AIsystems. This makes her justifably the best candidate for being entitled to authorship.

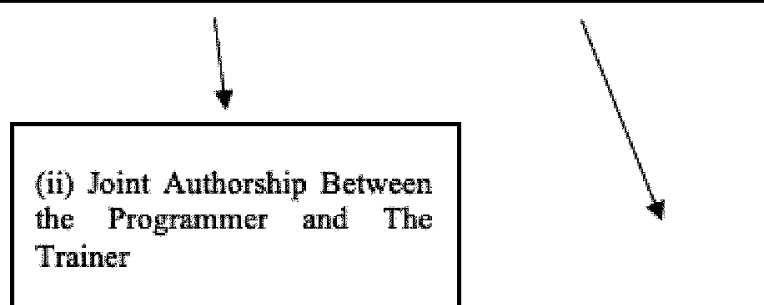

- Training neural networks are of crucial to generate better results.

- In case the programmer and the traner are not same entity, the cmployment relationship between them is decisive for anthorship.

- In case of the absence of any clause under the employment agreement, or any such agreement joint authorship provisions should apply to $\mathrm{Al}$ generated works.

\section{(iii) The User}

- The programmer could prefer to distribute creative Al-systems, and many users would lawtully obtain them.

-If the agreement provisions allow users to be authorship of Al-generated works, then the opportunity to improve the output of Al-system should be given to the user, thereby increases the competition.

\section{CONCLUSION}

Copyright is a reflection of technology. Historically, it has been shaped by developments in photography, sound recording and the performing arts. ${ }^{301}$ It is unavoidable that AI- technology will soon show its impact on the copyright regime and that the effect of technology has

${ }^{298}$ Bridy, supra note 57, at 27 (proposing to import the definition embodied in the CDPA despite the fact that her proposal is in the context of a work made for hire); Denicola, supra note 286, at 286; Guadamuz, supra note 159, at 185.

${ }^{299}$ See, e.g., Nova Productions Ltd v. Mazooma Games Ltd., [2006] EWHC 24 (Ch) (Kitchin J. held that the programmer should be entitled to the authorship of the composite frames because he is the person who makes necessary arrangements by designing many elements of the game, the rules and logic, and writing the underlying computer program. Although the work in question is a derivative work arising from the user's interaction, the provision is broad enough to encompass such instances.).

${ }^{300}$ See supra note 294 and accompanying text.

${ }^{301}$ See supra notes 164-68 and accompanying text. 
not always been consistent. AI-systems seem more autonomous and unforeseeable compared to existing technologies, yet the nature of technology itself provides this facilitation. ${ }^{302}$ A parallel argument was done for the photograph machine as being a merely mechanical process. ${ }^{303}$ It was acknowledged that there was no human intervention during the creative process in the beginning of the twentieth century although it was later recognized by legislative and juridical bodies as a copyrightable subject matter. ${ }^{304}$

It has been argued through this note that AI-systems have not acquired all the features that humans possess-such as free will, intention, consciousness, and the like. ${ }^{305}$ This does not change the fact that AI can generate works that not even the creators of the system could envisage. Moreover, the claim that creativity requires consciousness, intentionality or emotions is not certain in respective disciplines and remains highly contentious. ${ }^{306}$ Therefore, it has been suggested that a Turing-like test would provide a practical solution for the Courts to assess the creativity embodied in AI-generated work objectively. ${ }^{307}$ According to the test, the Courts should accept AI-generated work as copyrightable subject matter only if an AI-generated work cannot be differentiated from a human work and possesses as much aesthetic value as a work of the same standard produced by a human would. ${ }^{308}$ Since technological differences and economic considerations are strongly tied to the expansion of authorship, there are no constitutional or statutory obstacles to excluding AI-generated works even though the work originates in an algorithmic entity. ${ }^{309}$ The objective approach that investigates whether the work was not copied should suffice to prove that a work is copyrightable. ${ }^{310}$ Otherwise, excluding AI-generated works from copyrightability without any objective justification would be hypocritical since high-tech computers are already widely and efficiently employed in industries to generate works.

At the same time, the underlying utilitarian grounds for copyright generally-i.e., to address potential market failure by creating temporary monopolies to incentivize creative endeavors-can

${ }^{302}$ See supra note 289 and accompanying text.

${ }^{303}$ Burrow-Giles, 111 U.S. at 56.

${ }^{304} \mathrm{Id}$. at $58-59$.

${ }^{305}$ See supra note 207 and accompanying text.

${ }^{306}$ See supra notes 90-100 and accompanying text.

${ }^{307}$ See supra notes 103-05 and accompanying text.

${ }^{308}$ See supra notes 104-05 and accompanying text.

${ }^{309}$ See FAQ: Authorship and Ownership in U.S. Copyright Law, Author's Alliance,_https://www.authorsalliance.org/2014/05/20/authorship-and-ownershipfaq/\#TOC-1 (last updated May 20, 2014).

${ }^{310}$ Supra note 116. 
accommodate AI-generated works. ${ }^{311}$ Given AI productions costs are low, copyright duration can be shortened in the case of creative outputs. ${ }^{312}$ AI-generated works should not belong to the public, since the incentives to build the underlying AI-systems would disappear and end users would be reluctant to share their user-generated adaptations, gumming up innovation. ${ }^{313}$ We can take the monkey selfie case as an example. The photographer, Slater, was surely due a right to capture some reward for his investment of time, effort and skill in: (i) devising a scheme to have creative output generated by monkeys snapping photographs and; (ii) making the arrangements to do so in situ. ${ }^{314}$ This is plainly analogous to the programmer or the trainer's role in creating AI-systems. ${ }^{315}$ Regarding the user, he simply clicked the button to generate the photograph; no skill, labor or resources were expended by him to do so. ${ }^{316}$ However, it should be recalled that this possibility is reliant on contractual relationship with the programmer and the user, as we have witnessed that the output of photograph or sound recording machine belongs to the user. ${ }^{317}$ Although in these cases the user contributes more than AI-generated works ${ }^{318}$, the opportunity that the user could improve and contribute the output of AI-system should not be neglected and left to contractual restraints.

In most cases, there will be legal uncertainties regarding the contributions of the programmer, user or trainer and a broad provision that encompasses all circumstances would provide the courts a wide scope to deal with such disputes. The CDPA, which accepts the person who makes the necessary arrangements as an author of computergenerated work, is eligible to provide such scope and has been correctly applied by the United Kingdom's courts, and many countries followed this pathway. ${ }^{319}$ The United States legislative bodies should not hesitate to import such a definition which also serves the objective of international harmonization.

\footnotetext{
${ }^{311}$ See supra notes $175-80$ and accompanying text.

${ }^{312}$ Supra notes 2-4.

${ }^{313}$ Supra notes $184-88$.

${ }^{314}$ Supra notes 209-15.

${ }^{315}$ Supra note 232.

${ }^{316}$ Supra note 236.

${ }^{317}$ See supra notes $254-57$ and accompanying text.

318 See supra notes 223-224 and accompanying text.

${ }^{319}$ Supra note 294.
} 